\title{
Aerodynamic characteristics of a high-speed train crossing the wake of a bridge tower from moving model experiments
}

\author{
Jinfeng $\mathrm{Wu}^{1} \cdot$ Xiaozhen $\mathrm{Li}^{1}$ (1) C. S. Cai ${ }^{2,3} \cdot{\text { Dejun } \mathrm{Liu}^{4}}^{4}$
}

Received: 19 October 2021/Revised: 11 January 2022/Accepted: 17 January 2022/Published online: 5 March 2022

(C) The Author(s) 2022

\begin{abstract}
In a strong crosswind, the wake of a bridge tower will lead to an abrupt change of the aerodynamic forces acting on a vehicle passing through it, which may result in problems related to the transportation safety. This study investigates the transient aerodynamic characteristics of a high-speed train moving in a truss girder bridge and passing by a bridge tower in a wind tunnel. The scaled ratio of the train, bridge, and tower are 1:30. Effects of various parameters such as the incoming wind speed, train speed, and yaw angle on the aerodynamic performance of the train were considered. Then the sudden change mechanism of aerodynamic loads on the train when it crosses over the tower was further discussed. The results show that the bridge tower has an apparent shielding effect on the train passing through it, with the influencing width being larger than the width of the tower. The train speed is the main factor affecting the influencing width of aerodynamic coefficients, and the mutation amplitude is mainly related to the yaw angle obtained by changing the incoming wind speed or train speed. The vehicle movement introduces an asymmetry of loading on the train in the process of
\end{abstract}

Xiaozhen Li

xzhli@swjtu.edu.cn

1 Department of Bridge Engineering, School of Civil Engineering, Southwest Jiaotong University, Chengdu, China 610031

2 Department of Bridge Engineering, School of Transportation, Southeast University, Nanjing, Jiangsu, China

3 Department of Civil and Environmental Engineering, Louisiana State University, Baton Rouge, LA 70803, USA

4 College of Civil Engineering and Architecture, Jiaxing University, Jiaxing 314001, Zhejiang, China approaching and leaving the wake of the bridge tower, which should not be neglected.

Keywords Vehicle aerodynamics - Wind tunnel test . Moving train $\cdot$ Bridge tower $\cdot$ Shielding effect $\cdot$ Sudden change mechanism $\cdot$ Truss bridge

\section{Introduction}

The dynamic performance and safety of rail transportation are of great concern for long-span bridge development subjected to crosswinds. With the continuous improvement of train speed, not only the aerodynamic resistance of the train increases sharply, but a series of aerodynamic problems that endanger the train operation safety and reduce the comfort of passengers appear to be solved urgently. These aerodynamic challenges are associated with a high-speed train passing through tunnels, bridge towers, and encountering one another. The running safety of the train and the coupling effect among the crosswind, moving vehicle, and bridge structure are greatly concerned issues and have been investigated by many scholars [1-4]. Xu and Guo [5] and Cai and Chen [6] built a three-dimensional wind-road vehicle-bridge framework to analyze the dynamic responses of the vehicle-bridge system in a windy environment. Li et al. [7] established a wind-vehicle-bridge coupled model for railway vehicles. Xu et al. [8,9] developed a vehicle-track modeling method to simulate the dynamic interaction. Liu et al. [10] then extended the safety analysis of the vehicle on the railway bridge by taking into account of the vibration effect of the track structure and accordingly 
proposed a wind-train-track-bridge interaction system for research.

The bridge engineering community has presently entered a new era which the construction of bridges crossing mountainous and oceanic terrain or connecting islands needs to be addressed [11, 12]. Long-span bridges are favored by designers because of its strong crossing ability and convenient navigation. The spans of the suspension and cable-stayed bridges have been challenging new limits. The size of the bridge tower also increases with a large proportion even reaching tens of meters along the longitudinal bridge direction. The existence of the bridge tower will change the windy environment around the deck $[13,14]$. The authentic aerodynamic forces of the vehicle are determined by the flow field around it. In this scenario, the sudden change of transverse wind speed in the tower region is more likely to induce the lateral instability of vehicles and handling/controllability problem for the driver $[15,16]$. This lies in the dramatic change of aerodynamic forces acting on the vehicle as it passes through the bridge tower. When the vehicle drives through the tower, the vehicle will be tightly blocked. The wind loads acting on the vehicle will decrease as it enters the tower region, and then increase as it leaves the region, experiencing a sharp change with a high risk that the vehicle can be turned over. The flow field near the tower region is complicated. For better evaluation of the running safety of the vehicle and improving the ride comfort of passengers as well as to provide perspectives for accident prevention, the study on the aerodynamic characteristics of the vehicle crossing the wake of the bridge tower is of critical importance.

The characteristics of the aerodynamic forces acting on the vehicle can be achieved through computational fluid dynamics (CFD), wind tunnel experiments, and full model field tests. Due to the complexity, high cost, and difficulty of implementation of the actual vehicle test, the former two methods are commonly adopted. The aerodynamic forces acting on a vehicle model were typically obtained using stationary scaled models in the initial stage of the study [17-20]. By considering the moving nature of vehicles with critical disruptions to aerodynamic performance, a more appropriate experimental system which can deal with moving aerodynamic problems is in need which can reveal the real-time characteristics of aerodynamic forces acting on the vehicle [21-23]. Bocciolone et al. [24] attempted to achieve this by releasing a train model from a specifically designed ramp to mimic its acceleration. To explore wind induced forces and pressures on the vehicle model, Dorigatti et al. [25] considered in detail the differences between moving model experiments and static experiments. In recognizing the technical challenges and limitations, Xiang et al. [26] designed a relatively long and smooth guide-way to minimize the experimental errors for testing the aerodynamic forces and moments on the vehicle. Research on the aerodynamic characteristics of vehicles has been technically able to study the moving condition, and the train speed has been greatly improved as a result.

As far as the bridge towers are concerned, a vehicle crossing the wake of the tower may experience a sudden change in the aerodynamic loads on it which can potentially cause serious traffic accidents. Several researchers have attempted to qualitatively exhibit the variation of aerodynamic forces on vehicles as they pass through the wake of the tower [27-29]. Results reported in Charuvisit et al. [30] indicated that there was an asymmetry in the variation of the aerodynamic loads when the vehicle was approaching and leaving the tower wake. In Argentini et al. [31], a description of aerodynamic loads on a high-sided vehicle located in the wake of a bluff tower was presented for the cases with and without localized wind shielding near the tower. Wang et al. [32] simulated the aerodynamic forces on a stationary road vehicle in the wake of a bridge tower using CFD and compared the simulation results with wind tunnel test results for the first time.

However, the results of the aforementioned studies are mainly focused on vehicles at exposed sites such as exposed bridges, ground surfaces, viaducts, and embankments. Only a few studies have been carried out on vehicles running across a complicated bridge structure such as a truss girder bridge, which is instinctively different in structure and the interferences arising from it must be considered. The design of a truss bridge can result in significantly different flow patterns in crosswind conditions. The atmospheric boundary layer (ABL) differs significantly from that of largely exposed bridges as well as the aerodynamics of vehicles immersed in them, requiring the aerodynamic forces of vehicles running inside a truss bridge to be investigated as a standalone study. For the consideration of transient vehicle movement, which is inherently different from stationary testing, a long travel distance for the vehicle is required such that it can complete an acceleration and deceleration process. Thus, the scaled ratio of the bridge needs to be accordingly smaller, and the bridge model is relatively longer than that of typical bridges. This in turn requires the wind tunnel to be able to accommodate the device in it. Li et al. [33] developed a novel test system composed of a steel-truss bridge model, a CRH3 train model, a motion driving system, and a test instrumentation and acquisition system to measure the aerodynamic characteristics of a high-speed train passing through a truss bridge. The scaled ratio of both the bridge and the vehicle was 1:30. In accompanying work by Wang et al. [34], the shielding effect from the truss bridge on the aerodynamic forces of the vehicle was further experimentally investigated with vehicle both being stationary and moving and was compared with the simulation results from 
a numerical CFD model using the dynamic mesh method. Influencing factors of the incoming wind speed, train speed, and wind angle on the transient vehicle aerodynamic characteristics were also investigated. Yao et al. [35] adopted a new overset mesh approach to consider the motion of trains and its effect on the aerodynamics of the train-truss bridge system under crosswinds. The computed results were validated with the measured ones from wind tunnel experiments. In addition to considering the complex supper structure of the bridge, introducing the bridge tower can produce a sudden change in the aerodynamic forces on the vehicle passing through it. However, the sudden change mechanism of the aerodynamic forces acting on the vehicle is rarely studied, yet these are of great importance for designers to have a comprehensive understanding of the aerodynamic characteristics of vehicles on bridges and/or for managers to adopt effective countermeasures to ensure the traffic safety on the bridge.

In this study, an experimental investigation into the changes in aerodynamic loads on a high-speed train due to the presence of the bridge tower is presented while also considering train motion. An innovative moving vehicle device which can apply measurements with shelters (e.g., the truss bridge, bridge tower, oncoming vehicle, wind barrier, and tunnel), compel the vehicle to a high driving speed, and adjust incoming wind directions, was developed. A truss girder and a typical high-speed train geometry were selected as the prototype with bridge towers at both sides of the deck with a scaled ratio of the bridge, train, and tower of 1:30. Systematic experiments were performed to investigate the variation of aerodynamic forces on the train as well as its sudden change mechanism as the train passes through the wake of the bridge tower. This investigation considers the influences of various parameters such as the incoming wind speed, train speed, and yaw angle which represents the first step toward a larger research project. The final goal of this research is, in fact, to put forward effective countermeasures like wind barriers to address issues associated with the sudden change in aerodynamic loads on the train and to assess the running safety of the train and the riding comfort of passengers when the train is approaching and leaving the wake of the tower, which will be discussed in detail in its accompanying paper.

\section{Models and experimental configuration}

\subsection{Train model}

In consideration of the common high-speed train types running in the Chinese railway, a typical train prototype was employed in the experiment and was simplified into a three-car train model composed of a head car, a middle car, and a tail car, as shown in Fig. 1. The simplification was based on the work by Cooper [36], which suggests that a decrease in length will not alter the aerodynamic characteristics of the flow as long as the total length remains above the limit, because the certain distance of the flow characteristics downstream the nose (less than a head car length) is more or less constant. Therefore, the middle car was used to simulate the fairly long middle car body of the train, and the head car and the tail car, as their names imply, were used to model the front car and the rear car, respectively. In addition, the head car and the tail car were basically used as transitional segments as their streamlined geometric shape can weaken the effect of the ambient flow around them. The flow structure around the middle car is recognized more stable, thus the aerodynamic forces acting on the middle car were tested in this study.

Further simplifications, such as neglecting the mirrors, windshield wipers, and mechanical parts, were made during the train model production process. The wheelsets and the bogies were also excluded in the modeling. In order to reduce the inertia effect as much as possible in the acceleration and deceleration processes, the train model adopted a light wood material for the car body and had it hollowed to achieve weight loss, while the high-quality wood could achieve high stiffness to ensure the accuracy of the aerodynamic measurements on the train model. The length of each car model is $500 \mathrm{~mm}$, and there is a small gap between them to ensure the measurement of the aerodynamic loads on the middle car that is independent. The mass of the head car, middle car, and tail car is 700, 980, and $820 \mathrm{~g}$, respectively.

\subsection{Bridge deck model}

There is mutual aerodynamic interference between vehicles and bridges under crosswinds. Some achievements have been made in the research of aerodynamic characteristics of trains in exposed environment, such as on the ground, subgrade, viaduct, or an open bridge structure [37-41]. However, only a few studies have been carried out on the aerodynamic interference effects of complex bridge structures (such as truss girder bridge) on trains. In recent years, due to the consideration of economy and traffic volume, the advantages of highway-railway bridges are more and more obvious, and they are favored by bridge designers. Different from the open bridge structure, when wind flows through the truss girder bridge, the unique form of the structure will result in complex flow characteristics around it, which also has a great impact on the aerodynamic characteristics of trains running inside the bridge.

A long-span cable-stayed bridge on the Shanghai-Nantong HSR (high-speed railway) was selected as the bridge 


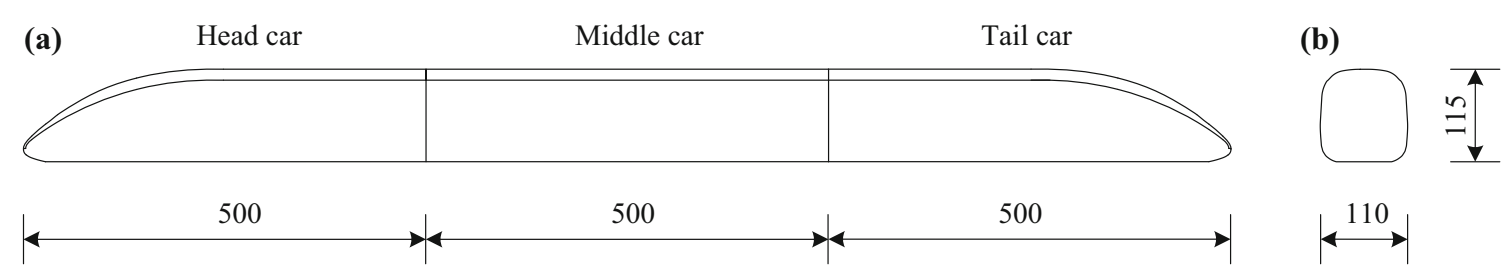

Fig. 1 Three-car train model (unit: $\mathrm{mm}$ ): a elevation view; $\mathbf{b}$ end view

prototype to investigate the effect of a bridge deck on the aerodynamic loads on a train. The total length of the deck model is $14,000 \mathrm{~mm}$ with 30 truss sections, each of which is $593.3 \mathrm{~mm}$ in height and $466.7 \mathrm{~mm}$ in length, respectively, as shown in Fig. 2a. The truss plane is triangleshaped with vertical web members. The cross-section is constant, and the width of the deck is $1,200 \mathrm{~mm}$ with the distance of $600 \mathrm{~mm}$ between two adjacent truss planes (see Fig. 2b).

The bridge deck model is made of wood with high rigidity and was manufactured based on simplifications by neglecting handrails, side and central protection rails and maintenance channels. The deck is separated from the upper train model so that the aerodynamic force measurements on the train cannot be affected by the lower deck.

\subsection{Experimental configuration}

The wind tunnel tests were carried out in the XNJD-3 wind tunnel at Southwest Jiaotong University. The XNJD-3 wind tunnel is a large closed type boundary layer wind tunnel, with a test section of $22.5 \mathrm{~m}$ in width, $36.0 \mathrm{~m}$ in length, and $4.5 \mathrm{~m}$ in height, respectively. This large-scaled wind tunnel, on one hand, can increase the scale ratio of the model so that some small accessories can be accurately simulated. On the other hand, it can adapt to the wind tunnel test requirements of super long-span bridges. The achievable maximum mean wind speed in the tunnel can reach $16.5 \mathrm{~m} / \mathrm{s}$, and the minimum mean wind speed can be as low as $1 \mathrm{~m} / \mathrm{s}$.

Capitalizing on the large width of the test section, an innovative testing device which can accelerate the train model to a high driving speed and adjust incoming wind directions was developed, as displayed in Fig. 3. Based on this device, a series of wind tunnel experiments were performed on a moving train model, to investigate how the aerodynamic forces on the train vary as it was crossing the wake of a tower. The train model was placed inside the truss girder, and it was only moving on the windward side. The total length of the bridge deck model is $14,000 \mathrm{~mm}$, and is divided into four segments for installation, between which there is a small gap to separate them from each
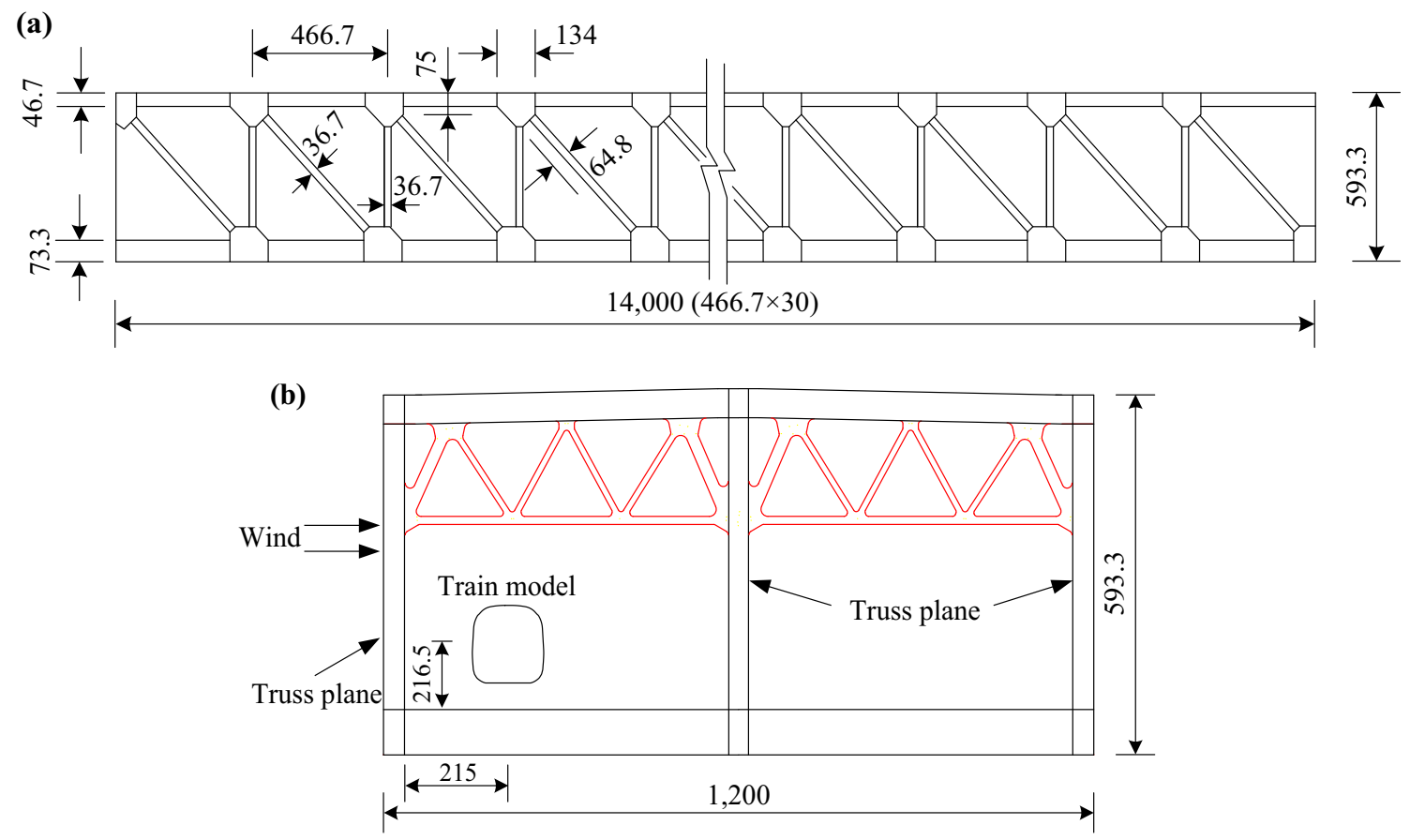

Fig. 2 Bridge deck model (unit: $\mathrm{mm}$ ): a side view; b cross section 


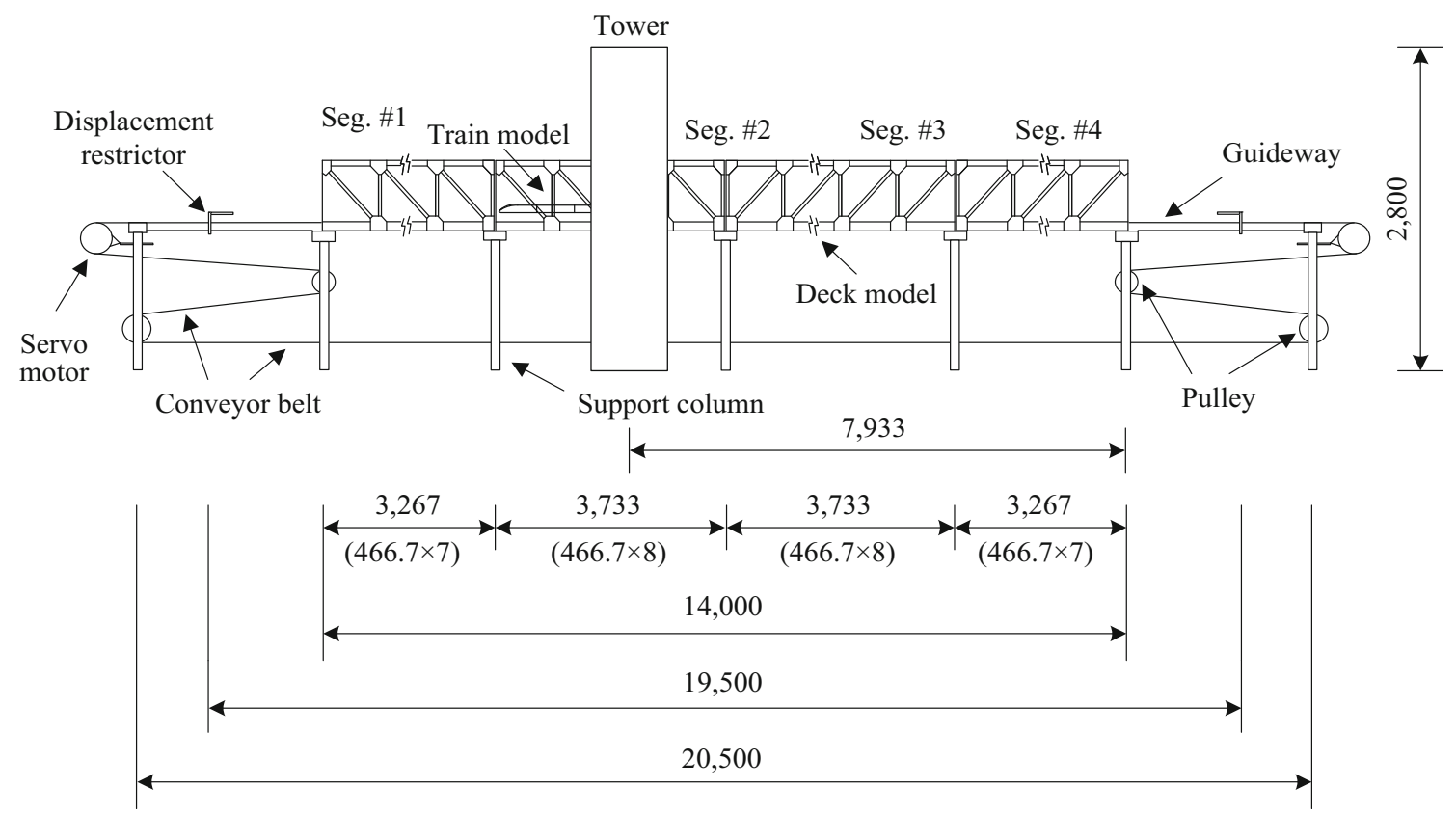

Fig. 3 Schematic diagram of experimental configuration (unit: $\mathrm{mm}$ )

other. The bridge system and the entire testing system are erected by support columns. The side and middle segments contain 7 and 8 internodes, respectively. In order to prevent the train model from rushing out of the guide-way due to the inertial effect, displacement restrictors are set at both ends of it. The distance between the restrictors i.e., the actual operating distance for the train model is $19,500 \mathrm{~mm}$, and the total length of the guide-way is $20,500 \mathrm{~mm}$.

The train model is actuated by a servo motor with transmissions by pulleys and a synchronous conveyor belt, which is made of aluminum alloy material as flat and very rigid, ensuring smooth operation of the train model. The train model can accurately run at a set speed, and maintain this speed after the acceleration is completed. The interval of both the acceleration and the deceleration is $0.5 \mathrm{~s}$. Taking into account the operating distance for the train model, the maximum running speed is set to be $15 \mathrm{~m} / \mathrm{s}$ to ensure that the actual performing of the train model is within the testing area. It also guarantees the interval of a certain constant speed when the train model moves is long enough for signal processing and aerodynamics analyses. The motion system can realize bi-directional driving of vehicles, forward and backward, greatly improving the efficiency of tests and test cases.

The data acquisition system is another important component of the whole testing device. It is mainly composed of a force testing balance, a sensor, a signal receiver, and a connecting cable, as shown in Fig. 4. The force testing balance is installed at the centroid of the middle car to measure the aerodynamic forces of the middle car. The signal receiver is mounted on the head car to collect data from sensor via the connecting cable. Then, the signal receiver transmits the data to a remote computer synchronously and wirelessly which, compared to most of the conventional long wire experiments, not only ensures the stability of the flow field around the vehicle model, but avoids the potential safety problems caused by wire winding or towing. More importantly, the wireless data acquisition method provides a good premise for testing on vehicles passing through shelters such as bridge towers or wind barriers. The whole device makes the aerodynamic tests on trains more convenient and accurate, and details about the testing device can be referred to $\mathrm{Li}$ et al. [33].

\subsection{Wind tunnel test on site}

Figure 5 shows the relative position of tower models to the deck. The distances between the tower center and two ends of the deck are 6,067 and $7,933 \mathrm{~mm}$, respectively. The tower models are made of wood, 2,800 $\mathrm{mm}$ in height, and are set on both sides of the deck model. The lateral and longitudinal width of the tower cross-section are 505 and $660 \mathrm{~mm}$, respectively.

The motion system can drive vehicles in both directions, forward or backward, which greatly improves the efficiency of the tests. The forward direction is the default positive direction set by the test module, as shown in Fig. 5, then the backward direction is the opposite direction of motion. According to the time history curve of the 

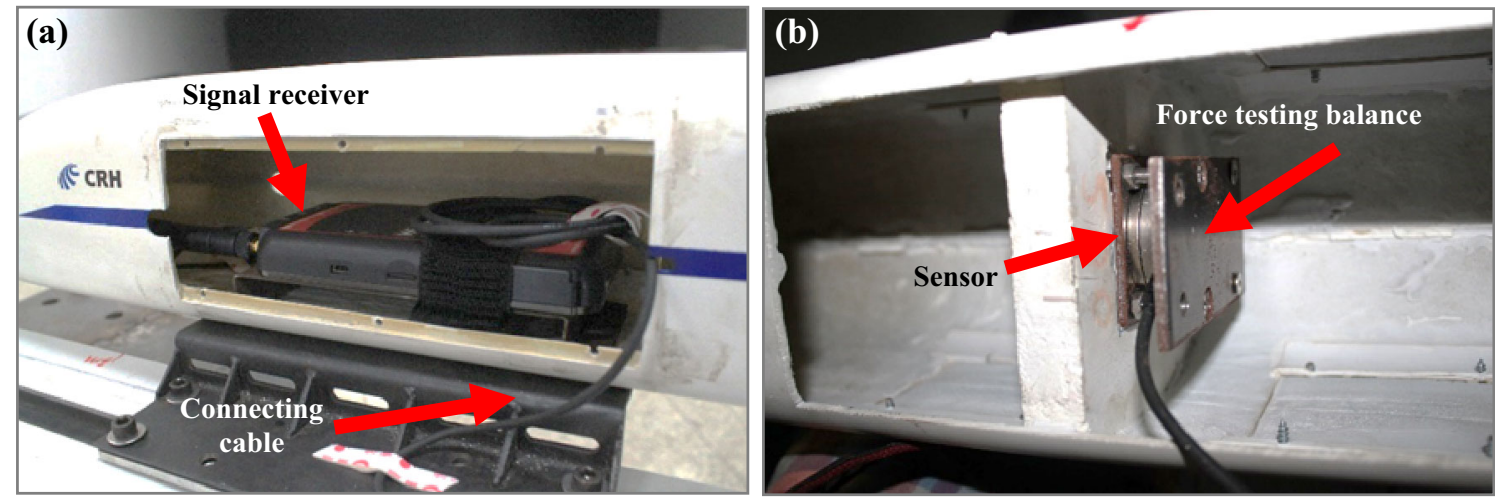

Fig. 4 Data acquisition system: a signal receiver in the head car; b force testing balance in the middle car [31]

(a)
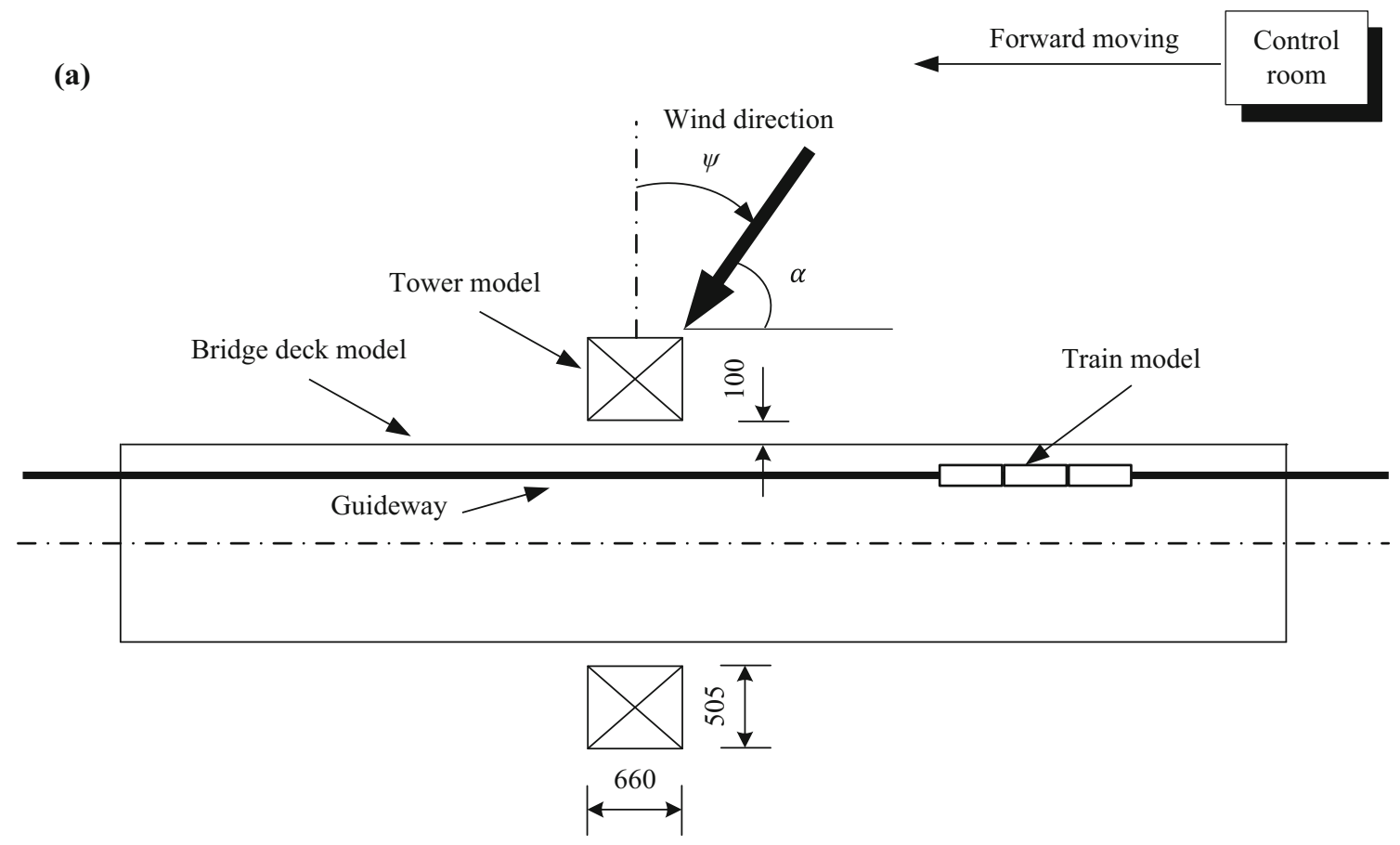

(b)

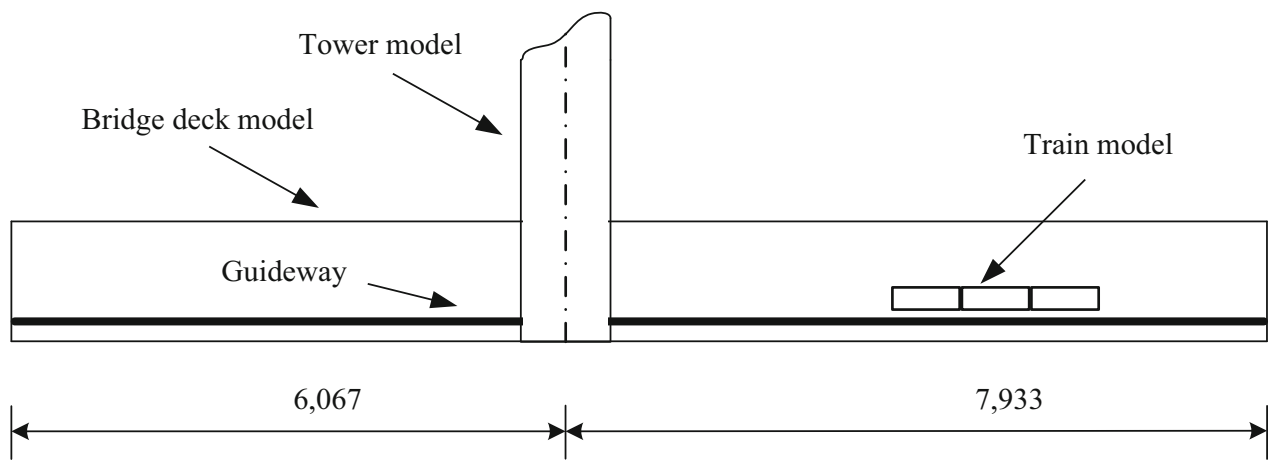

Fig. 5 Experimental configuration with tower models (unit: $\mathrm{mm}$ ): a top view; b side view 
longitudinal force coefficient, the operating direction can be distinguished.

The incoming direction of wind $\psi$ is assigned to be perpendicular to the deck, and $\alpha$ is defined as the wind angle i.e., the angle between the incoming wind velocity $U$ and the deck. The relationship between $\alpha$ and $\psi$ is $\alpha=90^{\circ}-\psi$, and the wind angle discussed in this study is $90^{\circ}$. The sampling frequency is set to be $1,024 \mathrm{~Hz}$, which is applicable for data analysis under different train speeds. In order to minimize the systematic errors and ensure the stability of the test system, each case was repeatedly tested for three times. The in-situ wind tunnel experiments of the three-car train model passing through the tower are shown in Fig. 6.

\section{Data process}

The wind forces and moments acting on the train model can be measured by the force testing balance. The directions of wind loads and velocity vector diagram of train model are displayed in Fig. 7. In this study, only the lift force $F_{\mathrm{L}}$, the side force $F_{\mathrm{S}}$, and the rolling moment $M_{\mathrm{R}}$ are investigated, corresponding to $F_{x}, F_{y}$, and $M_{z}$ in Fig. 7, respectively. The relationship between the wind velocity $U$ and the relative wind velocity to vehicle $U_{\text {res }}$ is as follows:

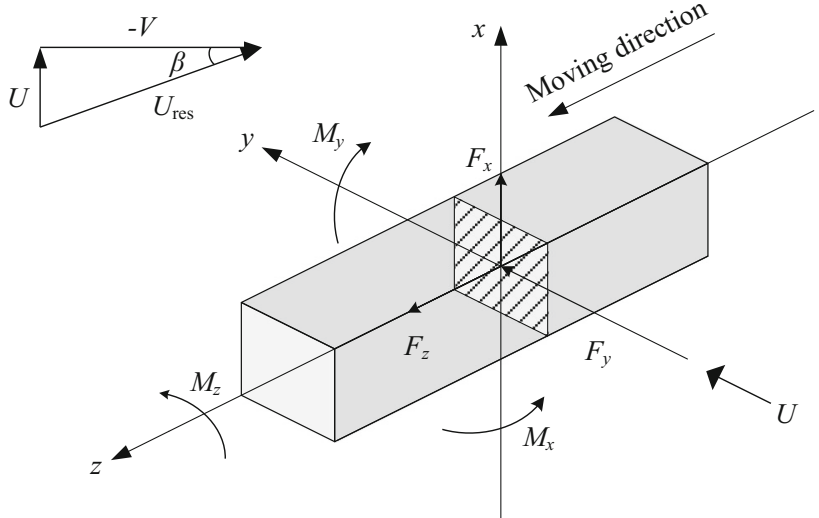

Fig. 7 Wind loads and velocity vector diagram on train model

$U_{\text {res }}^{2}=U^{2}+V^{2}$,

$U=U_{\text {res }} \cdot \sin \beta$,

$\beta=\arctan (U / V)$,

where $\beta$ is the yaw angle.

\subsection{Definition of train aerodynamic coefficients}

There are two typical definitions for train aerodynamic coefficients. One is defined according to the incoming mean wind speed perpendicular to the moving direction,
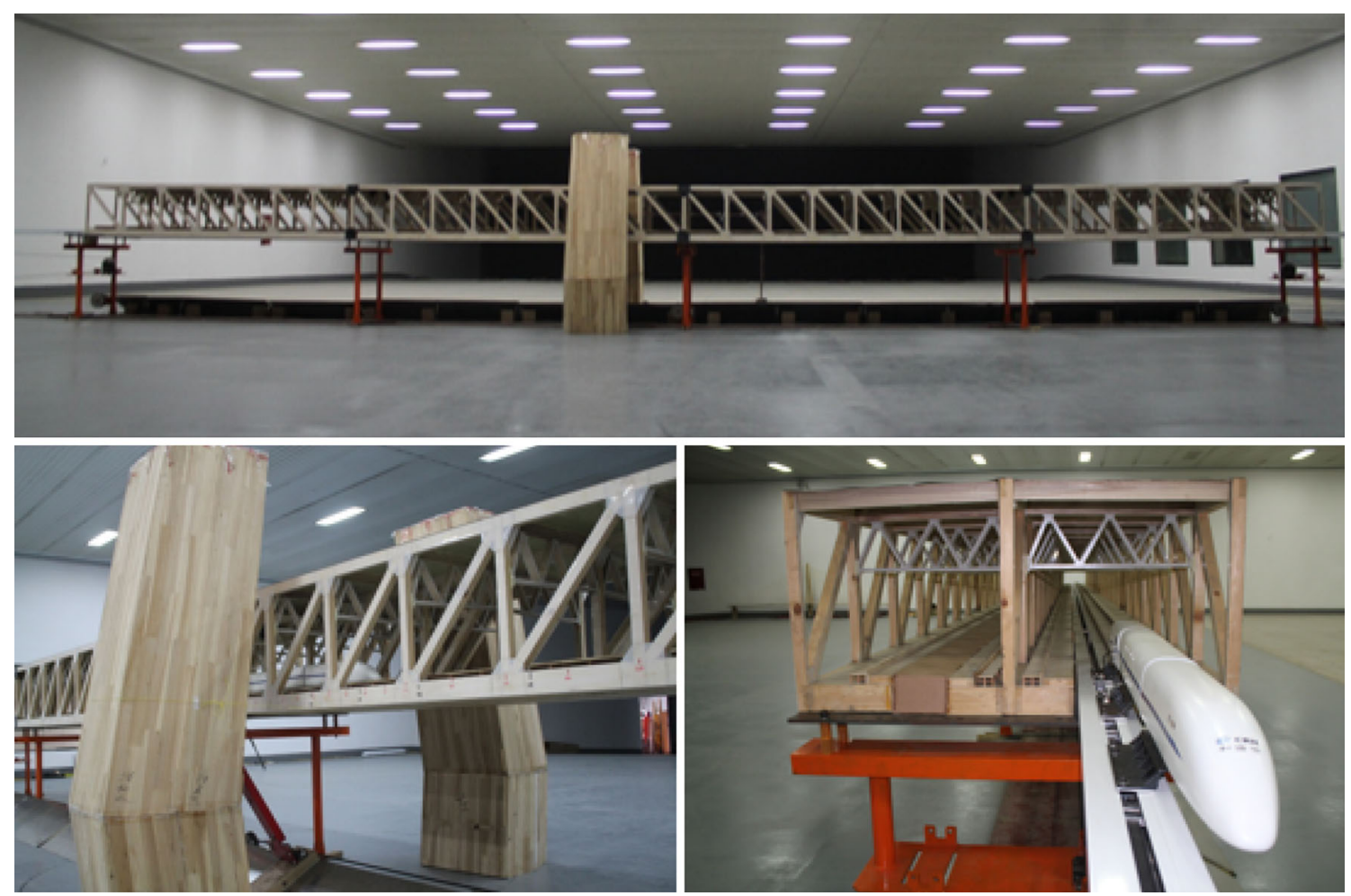

Fig. 6 Wind tunnel test on site 
which is convenient for further study, if any, such as the application of wind loads on vehicles in the coupled windvehicle-bridge vibration analysis. The expressions are as follows:

$C_{\mathrm{L}, \mathrm{I}}=\frac{F_{\mathrm{L}}}{0.5 \rho U^{2} B L}$,

$C_{\mathrm{S}, \mathrm{I}}=\frac{F_{\mathrm{S}}}{0.5 \rho U^{2} H L}$,

$C_{\mathrm{R}, \mathrm{I}}=\frac{M_{\mathrm{R}}}{0.5 \rho U^{2} B^{2} L}$,

where $C_{\mathrm{L}, \mathrm{I}}, C_{\mathrm{S}, \mathrm{I}}$, and $C_{\mathrm{R}, \mathrm{I}}$ are the lift force coefficient, side force coefficient, and rolling moment coefficient based on the first type of definition, respectively; $\rho$ is the air density; $U$ is the incoming mean wind speed; $B, H$, and $L$ stand for the width, height, and length of the middle car, respectively. The other definition is based on the resultant velocity of wind velocity and vehicle velocity (see Fig. 7) and can be written as

$C_{\mathrm{L}, \mathrm{II}}=\frac{F_{\mathrm{L}}}{0.5 \rho U_{\mathrm{res}}^{2} B L}$,

$C_{\mathrm{S}, \mathrm{II}}=\frac{F_{\mathrm{S}}}{0.5 \rho U_{\mathrm{res}}^{2} H L}$,

$C_{\mathrm{R}, \mathrm{II}}=\frac{M_{\mathrm{R}}}{0.5 \rho U_{\mathrm{res}}^{2} B^{2} L}$,

where $C_{\mathrm{L}, \mathrm{II}}, C_{\mathrm{S}, \mathrm{II}}$, and $C_{\mathrm{R}, \mathrm{II}}$ are the lift force coefficient, side force coefficient, and rolling moment coefficient based on the second type of definition, respectively.

On the basis of Eq. (1b), it can be easily deduced that the aerodynamic coefficients under these two definitions have the relation as follows:

$C_{i, \mathrm{II}}=C_{i, \mathrm{I}} \cdot \sin ^{2} \beta \quad(i=\mathrm{L}, \mathrm{S}, \mathrm{R})$.

The first definition is mainly employed for analyzing the influences of factors on aerodynamic characteristics of the vehicle in this study, and $C_{\mathrm{L}, \mathrm{I}}, C_{\mathrm{S}, \mathrm{I}}$, and $C_{\mathrm{R}, \mathrm{I}}$ are also written as $C_{\mathrm{L}}, C_{\mathrm{S}}$, and $C_{\mathrm{R}}$, respectively, in the following sections.

\subsection{Stability analysis of system testing}

The stability of the test system related to the reliable results of train aerodynamic coefficients are investigated by comparing the repeatedly tested cases through model tests. On one hand, it is to confirm the stability and consistency of system testing; on the other hand, it can ensure the effectiveness analysis of the target case, especially when there are errors with signals in one of the tests.
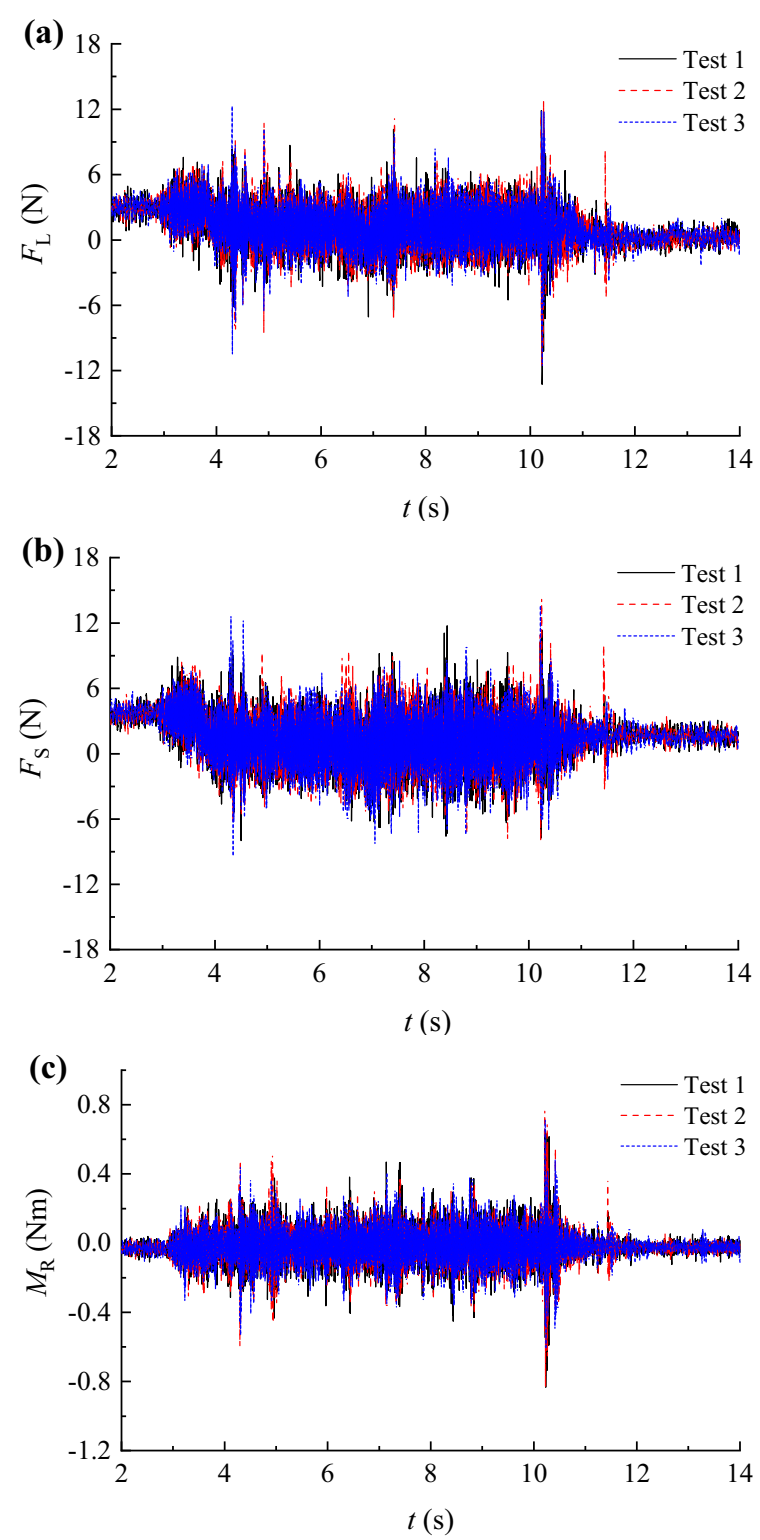

Fig. 8 Time history curves of three repeated tests: a lift force $F_{\mathrm{L}}$; b side force $F_{\mathrm{S}}$; c rolling moment $M_{\mathrm{R}}$

Figure 8 shows the time history curves of the aerodynamic loads on the train under three repeated tests with the train speed of $2 \mathrm{~m} / \mathrm{s}$ and the incoming wind speed of $10 \mathrm{~m} / \mathrm{s}$, respectively. Figure 9 displays the envelope analysis curves of the repeated tests for the convenience of comparison. The signal under three repeat tests shows the coincide trend and characteristics points. It can be seen that the results under three identical tests are in good agreement, i.e., the system has good stability which can meet the basic test requirements. With a comprehensive analysis of three test results, one test curve is selected as the final result for the case in this study. 

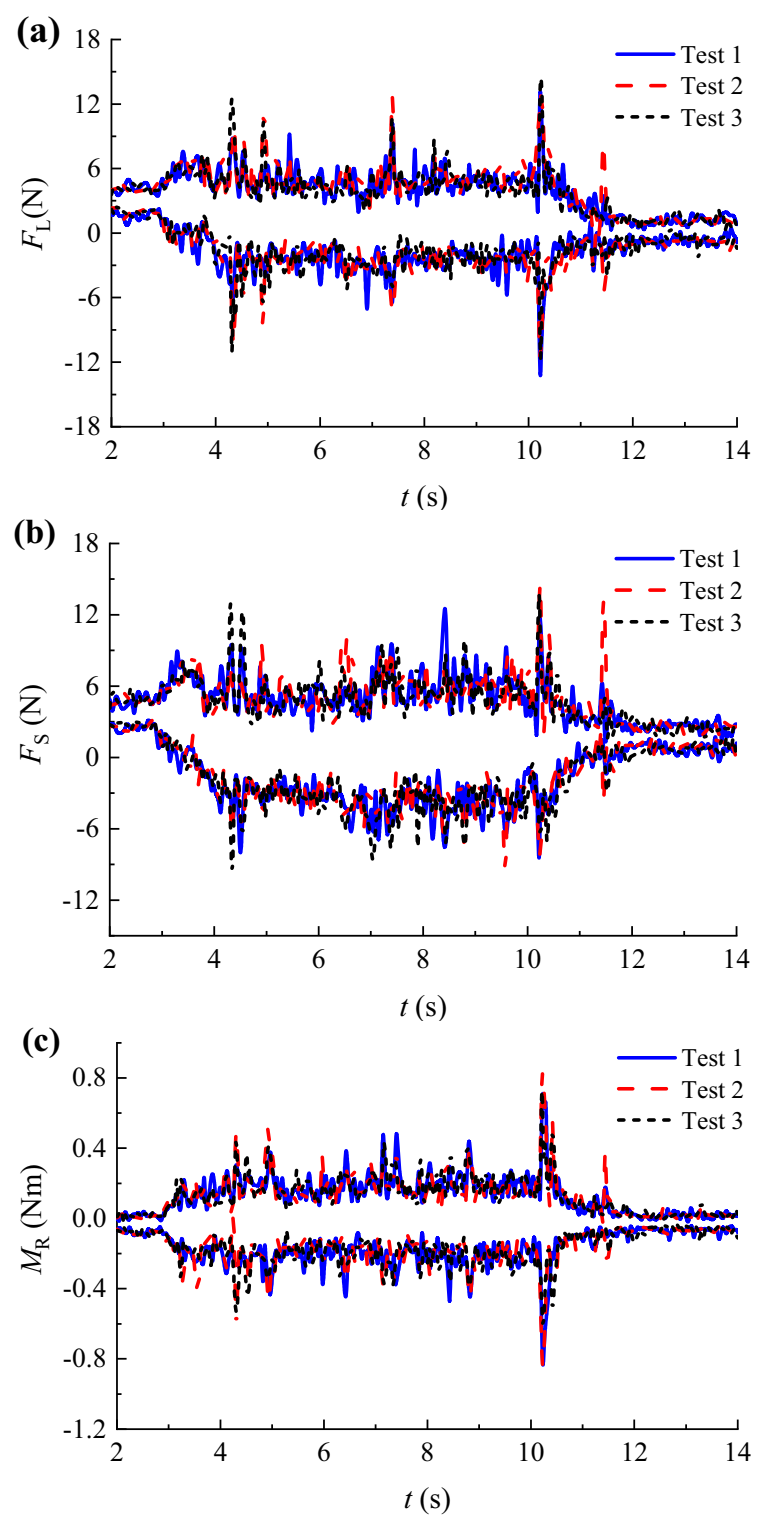

Fig. 9 Envelope curves of three repeated tests: a lift force $F_{\mathrm{L}} ; \mathbf{b}$ side force $F_{\mathrm{S}}$; c rolling moment $M_{\mathrm{R}}$

\subsection{Data analysis}

There are a lot of interference factors in the process of vehicle movement, such as rail irregularity, model vibration, and inertia effect, which will have a great impact on the accuracy of the test. Some shielding and vibration isolation measures have been taken in the test design, yet the introduction of interference signals cannot be completely avoided. Figure 10 shows the original time history curves of train aerodynamic coefficients under the train speed of $2 \mathrm{~m} / \mathrm{s}$ and the incoming wind speed of $10 \mathrm{~m} / \mathrm{s}$, where the longitudinal force coefficient defined by $C_{z}=F_{z} /\left(0.5 \rho U^{2} B L\right)$ is also given in Fig. 10d. It can be seen that the curve fluctuates strongly and obvious interferences exist in the test, which needs to be eliminated for better analysis of the data. $\mathrm{Li}$ et al. [33] indicated that using $0-10 \mathrm{~Hz}$ low pass filter can effectively eliminate the influence of interferences to process the original data. The filtered results are presented in Fig. 10, and it can be found that the time histories of the aerodynamic coefficients remain quite stable after filtering.

In order to investigate the variation of train aerodynamic coefficients in different movement stages (acceleration, constant speed, and deceleration) and in the process of entering the truss girder and the tower area, the filtered time history curves are re-plotted in Fig. 11.

The motion stages of the vehicle can be distinguished from the longitudinal force coefficient. The total running distance is $14 \mathrm{~m}$ set by the motion system, and the intervals of both the acceleration and the deceleration are $0.5 \mathrm{~s}$. Thus, the distances of the acceleration and the deceleration stage as well as the constant speed period can be calculated accordingly, as illustrated in Fig. 11. As shown by Fig. 11a, the vehicle is stationary, being basically zero. The vehicle starts to accelerate at $3.44 \mathrm{~s}$ with a negative acceleration owing to backward moving, opposite to the positive direction of the motion system. At $3.94 \mathrm{~s}$, the acceleration phase is completed, and the vehicle reaches the set constant speed of $2 \mathrm{~m} / \mathrm{s}$. The interval the vehicle runs at the constant speed is $6.5 \mathrm{~s}$, therefore, the theoretical time for initially decelerating of the vehicle should be $10.44 \mathrm{~s}$, which is exactly consistent with that in the longitudinal force coefficient curve. The vehicle stops at $10.94 \mathrm{~s}$, and the longitudinal force coefficient returns to around zero after the flow field is stable.

According to the changes of aerodynamic coefficients and in each motion stage, the moving process of the vehicle passing through the bridge with tower is segmented as follows:

S1: Stationary stage (vehicle outside the truss girder), $V=0$

S2: Acceleration stage, with an interval of $0.5 \mathrm{~s}$;

S3: Constant speed stage (vehicle outside the truss girder);

S4: Constant speed stage (vehicle entering the truss girder);

S5: Constant speed stage (vehicle inside the truss girder);

S6: Constant speed stage (vehicle through the tower area);

S7: Deceleration stage, with an interval of $0.5 \mathrm{~s}$;

S8: Stationary stage (vehicle inside the truss girder).

From Fig. $11 \mathrm{~b}-\mathrm{d}$, it is found that when the vehicle is entering the truss girder (S4) and passing through the tower (S6), the aerodynamic coefficients of the vehicle change significantly and both decrease (the rolling moment coefficient considering the absolute value), which indicates that the presence of the truss girder and bridge tower have a clear shielding effect on the vehicle. The aerodynamic 

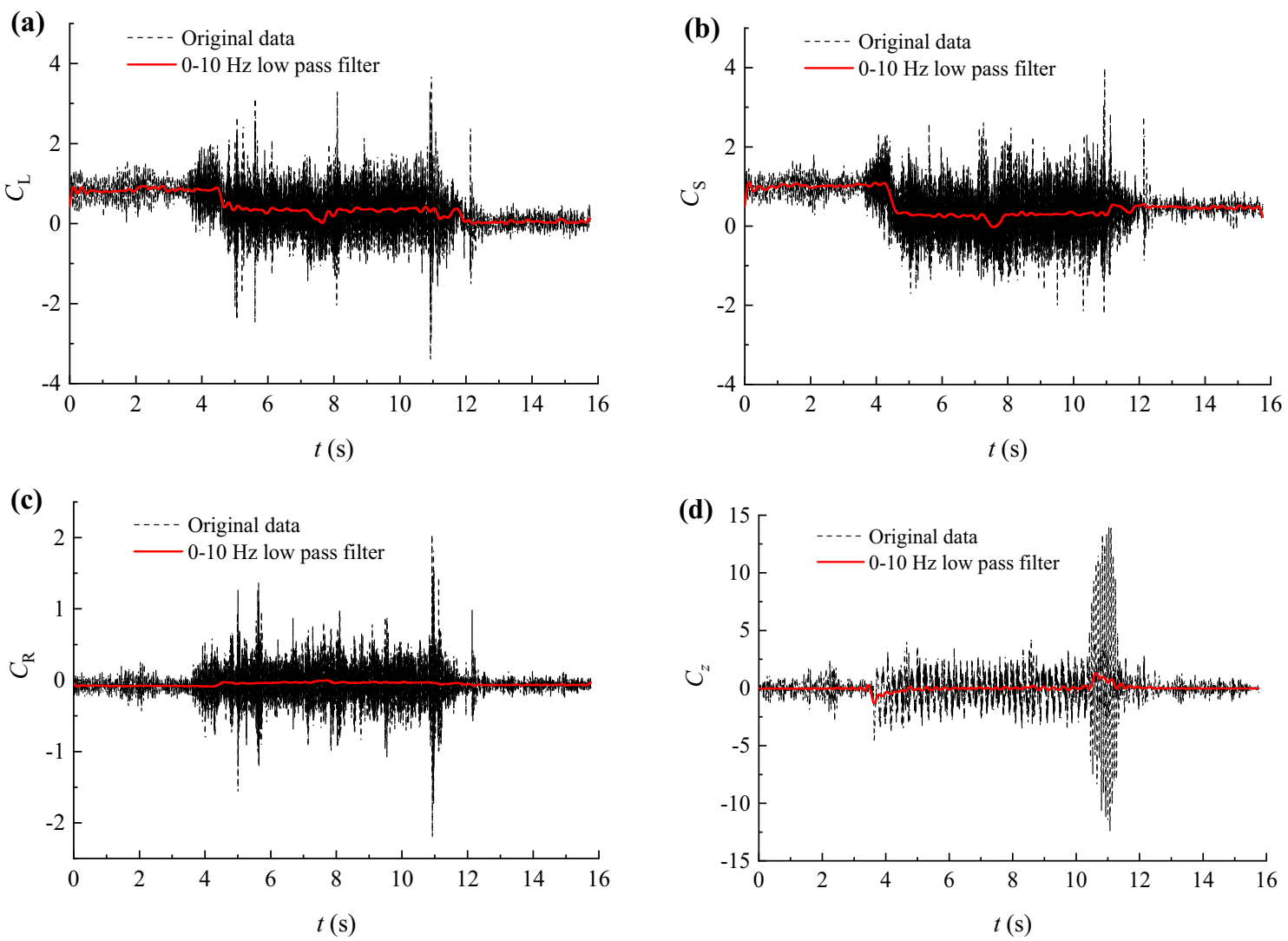

Fig. 10 Data filtering processing: a lift force coefficient $C_{\mathrm{L}} ; \mathbf{b}$ side force coefficient $C_{\mathrm{S}}$; $\mathbf{c}$ rolling moment coefficient $C_{\mathrm{R}} ; \mathbf{d}$ longitudinal force coefficient $C_{z}$

coefficients during other stages, including S1, S5, and S8, are relatively stable. The flow field is not yet stable in the initial 10.94-12.5 s in S8 since the vehicle has just stopped, and hence, the period of $12.5-15 \mathrm{~s}$ is regarded as the steady section of S8. One can find that when the vehicle is stationary, the aerodynamic coefficients in $\mathrm{S} 1$ are larger than those in $\mathrm{S} 8$ (absolute value for $C_{R}$ ) due to the shielding effect of truss bridge. The shielding effect is also found when the train runs from the uncovered stage S3 to stage S5. This indicates that whether the vehicle is in movement or not, the shielding effect of the truss structure should not be ignored. Similarly, the influence of the bridge tower on the vehicle crossing through it is also significant, which should be paid special attention to and considered in the analysis of vehicle aerodynamics.

Putting aside the variations in the tower area, when the vehicle is enclosed in the truss girder (S5 to S8), the aerodynamic coefficients change greatly and vary from each other from vehicle movement to stop. Compared with the dynamic condition, the lift force coefficient of the vehicle in stationary state decreases, while the side force coefficient and the rolling moment coefficient increase $\left(C_{\mathrm{R}}\right.$ considering absolute value). In the acceleration and deceleration stage (S2 and S7), the aerodynamic coefficients of the vehicle have no obvious change due to the instantaneity and short time interval, which is not promptly causing changes in the flow.

From the above analysis, it can be seen that the aerodynamic characteristics of the vehicle are closely related to the flow field, and the main factors leading to changes of it are shelters and vehicle motion. This study mainly discusses the shielding effect by the bridge tower as well as considering the influence of vehicle movement.

\subsection{Reynolds number dependency}

The Reynolds number has a significant effect on the flow around a vehicle model. In wind tunnel test, the influence of the Reynolds number should be avoided or weakened to ensure the reliability of test results. Normally, it is assumed that the aerodynamic force measurements on vehicles are independent from the Reynolds number when the Reynolds number is beyond a critical value. An approximate critical number in Baker [21] is $6 \times 10^{4}$, with wind tunnel tests on a 1:50 scaled vehicle model. In the work by Li et al. [33], it has been pointed out that when the Reynolds number goes beyond a critical one (about $4.5 \times 10^{4}$ ), the aerodynamic coefficients of the train model are considered less sensitive to the Reynolds 


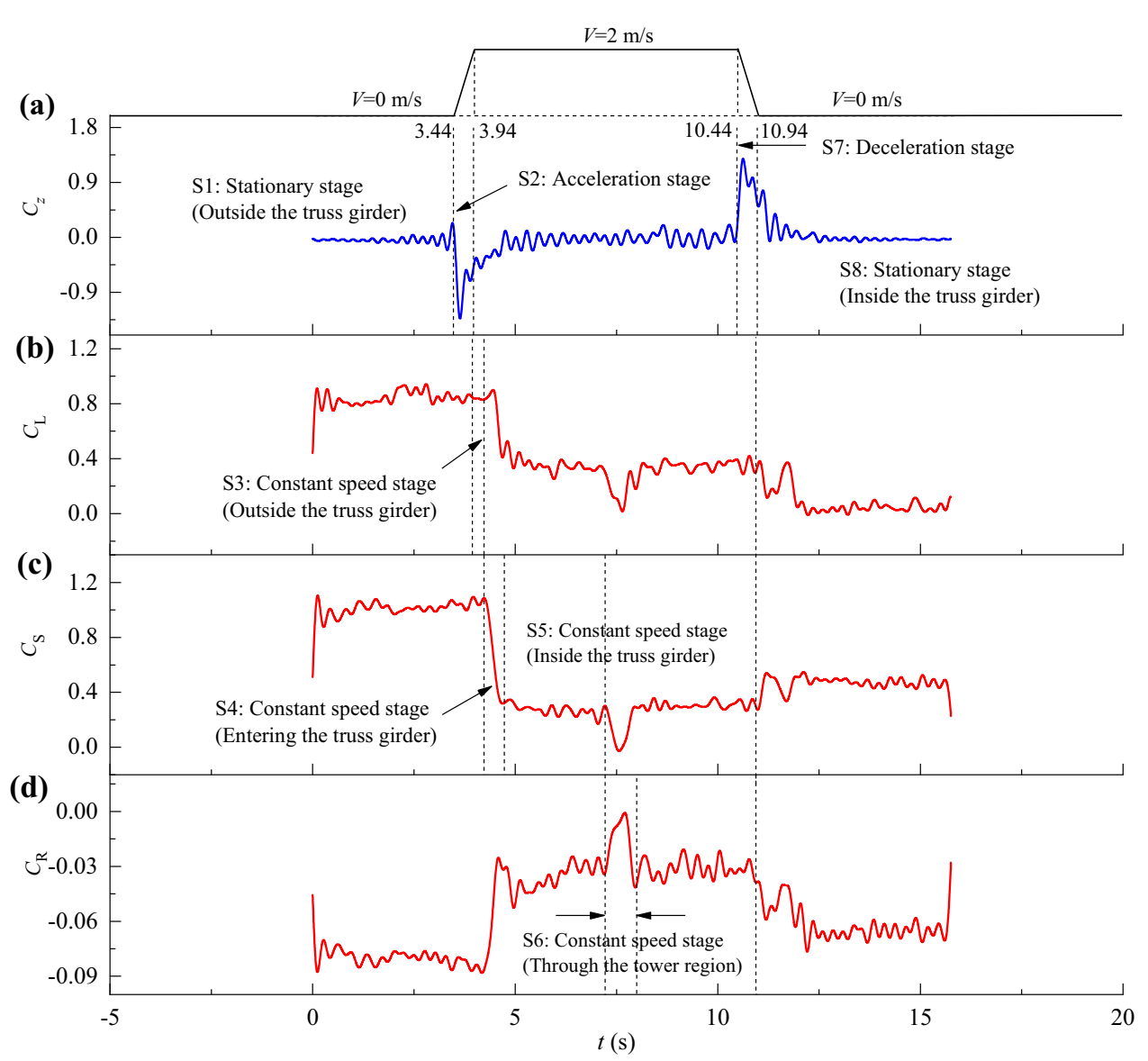

Fig. 11 Train aerodynamic coefficients in different stages: a longitudinal force coefficient $C_{z}$; b lift force coefficient $C_{\mathrm{L}}$; $\mathbf{c}$ side force coefficient $C_{\mathrm{S}} ; \mathbf{d}$ rolling moment coefficient $C_{\mathrm{R}}$

number. In the case, the results are obtained under the condition that only the train model movement are conducted on the guide-way without considering the influence of the truss bridge structure, which is known that it will have a significant effect on the flow around the vehicle. Specifically, the existence of the bridge structure will enhance the turbulence of the flow inside the truss girder where the train model travels.

For the present investigation with bridge structure involved, it is believed that the Reynolds number will get larger, far greater than the stated critical value of $4.5 \times 10^{4}$, leading to the aerodynamic coefficient measurement in a less Reynolds sensitive range. Therefore, the Reynolds effect on aerodynamics measurements is neglected in the following discussions.

\section{Results}

\subsection{Shielding effect of bridge tower}

The effects related to the presence of bridge tower are investigated by comparing the aerodynamic coefficients of the moving train passing through the bridge with and without tower (see Fig. 12). On one hand, it is to clearly understand the mechanism of the shielding effect of the tower on the aerodynamic performance of vehicles crossing through it; on the other hand, it is to confirm the validity and accuracy of the test device, especially when there are shelters (such as towers, buildings, etc.) in the field.

The time history curves of aerodynamic forces on the train under a certain driving speed can be converted into position curves through relevant processing of vehicle speed. The center of the tower model is referred as the location of $0 \mathrm{~m}$. The locations where the train model is approaching the tower are referred as the negative region, while the locations where the train model is leaving the wake are referred as the positive region, no matter the train model is moving forward or backward. For the convenience of description, the aerodynamic coefficient curve is roughly divided into three stages according to the position of the vehicle, namely, approaching tower, tower shielding area, and leaving tower. 

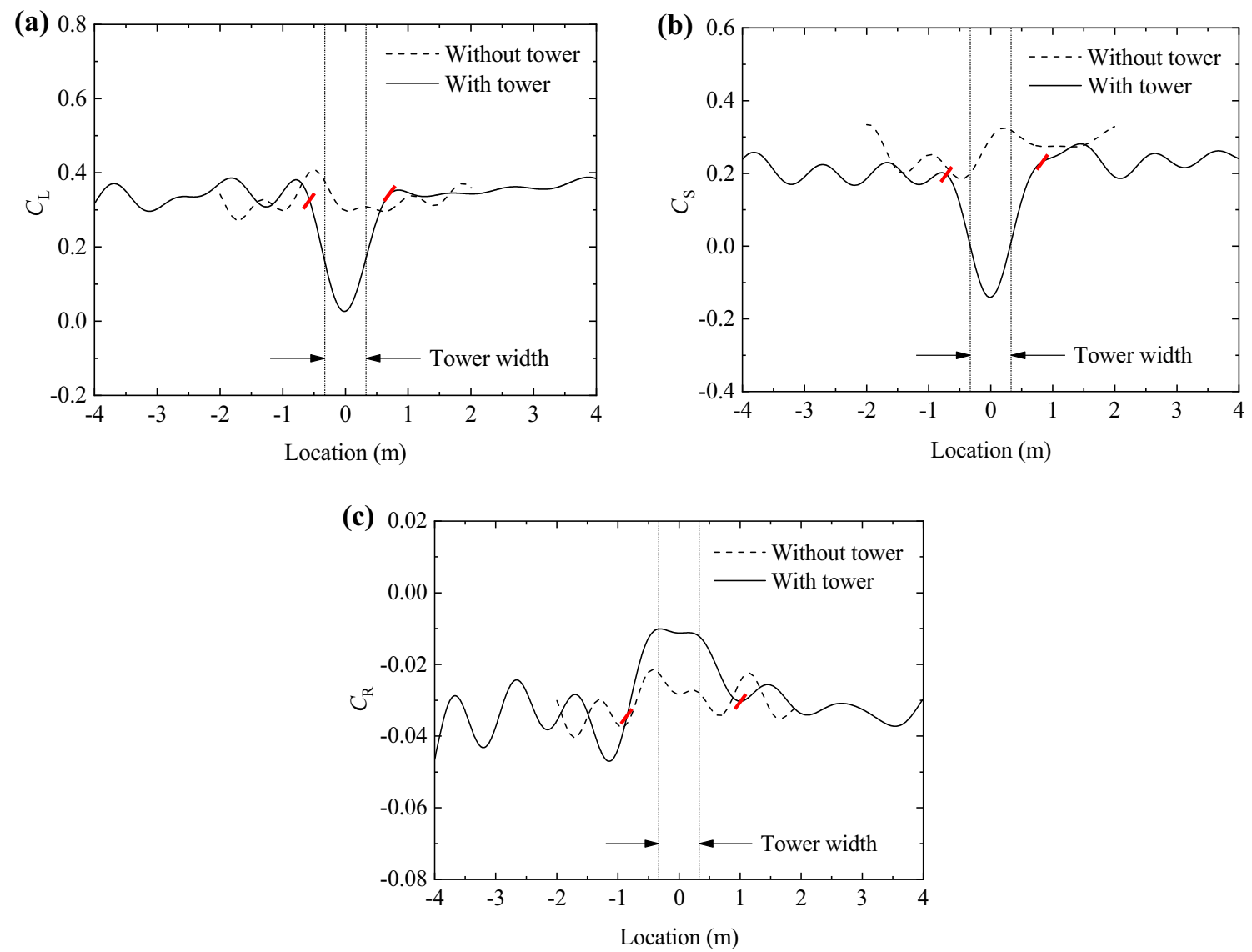

Fig. 12 Aerodynamic coefficients of train with and without tower: a lift force coefficient $C_{\mathrm{L}}$; b side force coefficient $C_{\mathrm{S}}$; $\mathbf{c}$ rolling moment coefficient $C_{\mathrm{R}}$

The incoming wind speed and train speed in this section are 10 and $4 \mathrm{~m} / \mathrm{s}$, respectively. From Fig. 12, it is found that the aerodynamic coefficients away from the tower region are well consistent with the case without tower, except a slight difference for the side force coefficient which is, however, within the scope of acceptance. Aerodynamic coefficients of train experience great mutations when it is passing though the bridge tower. The curves of the lift force coefficient and the side force coefficient first decrease as the vehicle approaches the tower wake and then increase as it leaves the wake. The side force coefficient even suffers a great decrease to negative area, indicating the side force changing the direction of force on the train. It is disadvantageous for train safety and explains the complexity of flow around the tower as well. While for the rolling moment coefficient which is small, its absolute value also experiences a sudden decrease and a sudden increase afterward as the train is passing behind the tower. Furthermore, the aerodynamic coefficients reach their mutation peak values at the tower region, demonstrating that the presence of the bridge tower has an obvious shielding effect on the train and has a significant influence on its aerodynamic characteristics.

Another aspect of the shielding effect of the bridge tower on the train is referred to the width of the sudden change area, which is much larger than the width of the tower itself, and the aerodynamic loads on the train present asymmetry when it approaches and leaves the tower. Changes of aerodynamic coefficients when vehicles cross through the tower can be achieved by means of wind tunnel test or CFD simulation [42-44]. However, there are few discussions on the mechanism and influencing factors of bridge tower shielding.

In this study, based on a long-span cable-stayed truss girder bridge, the aerodynamics of vehicles crossing through the wake of a tower were investigated via wind tunnel experiments. Two representative parameters, influencing width $d_{\mathrm{s}}$ and mutation amplitude $\Delta$, are defined to further study the sudden change mechanism of aerodynamic coefficients when passing by the bridge tower, as shown in Fig. 13. Taking one of the aerodynamic coefficients as an example, when the train is in the region of approaching tower and leaving tower, the mean values of its aerodynamic 


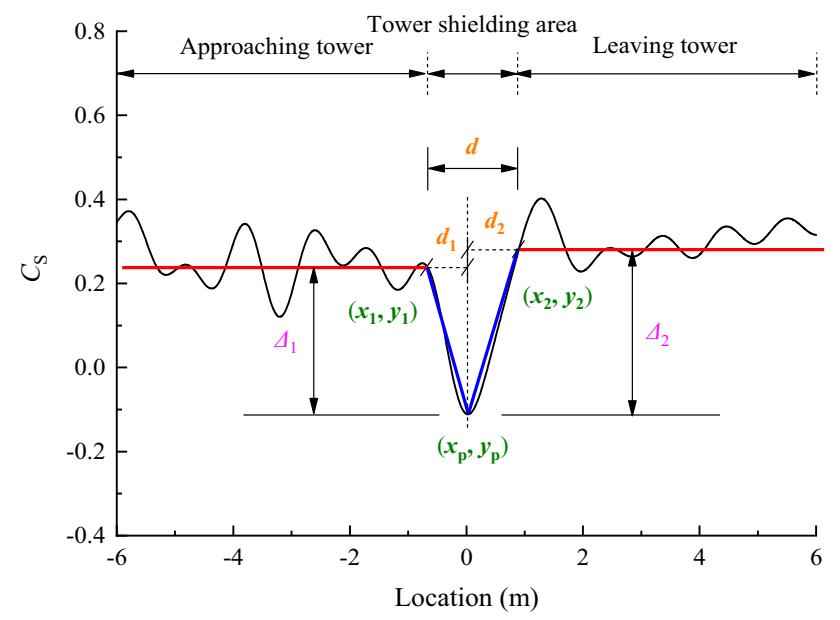

Fig. 13 Definition of influencing width and mutation amplitude

coefficients are denoted by $y_{1}$ and $y_{2}$, respectively, and horizontal lines with mean values intersecting with the aerodynamic coefficient curve can obtain points $\left(x_{1}, y_{1}\right)$ and $\left(x_{2}, y_{2}\right)$. The minimum point of the aerodynamic coefficient in the sudden change area is denoted by $\left(x_{\mathrm{p}}, y_{\mathrm{p}}\right)$. Then, some definitions are made as follows:

Influencing width:

$$
\begin{aligned}
& d_{1}=x_{\mathrm{p}}-x_{1}, \\
& d_{2}=x_{2}-x_{\mathrm{p}}, \\
& d_{\mathrm{s}}=d_{1}+d_{2}=x_{2}-x_{1} .
\end{aligned}
$$

Mutation amplitude:

$$
\begin{aligned}
& \Delta_{1}=y_{1}-y_{\mathrm{p}}, \\
& \Delta_{2}=y_{2}-y_{\mathrm{p}}, \\
& \Delta_{\mathrm{m}}=\left(\Delta_{1}+\Delta_{2}\right) / 2 .
\end{aligned}
$$

Taking a further analysis on Fig. 12, the mutation peak values of the aerodynamic coefficients at the tower region

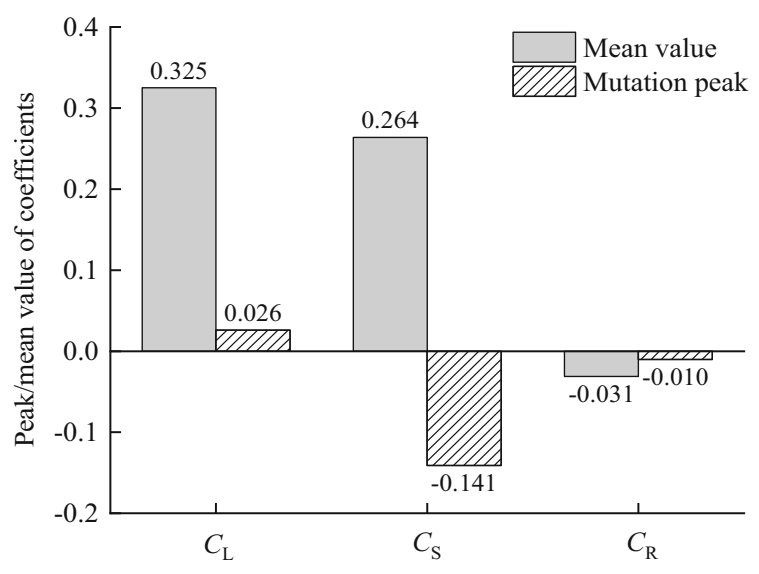

Fig. 14 Mutation peak and mean values of coefficients are quantitatively compared with mean values from the case without tower, as displayed in Fig. 14. The lift force coefficient decreases by $92 \%$; the side force coefficient decreases by $153 \%$; and the rolling moment coefficient increases by $68 \%$, quantitatively demonstrating an obvious shielding effect of tower. In the region of approaching tower and leaving tower, the mean values of the steady sections are obtained, and horizontal lines with mean values intersect with the aerodynamic coefficient curve, marked with red slashes in Fig. 12. Specifically, the width of the sudden change area for the lift force coefficient, side force coefficient, and rolling moment coefficient is 1.277 , 1.551 , and $1.856 \mathrm{~m}$, respectively, as illustrated in Table 1 . One can find that the width of the sudden change area for each coefficient is much larger than the tower width of $0.660 \mathrm{~m}$ (abscissa range from -0.330 to $0.330 \mathrm{~m}$ ), increasing by $1.93,2.35$, and 2.81 times, respectively. In addition, the initial and last intersection point exactly state the asymmetry in the aerodynamic loads when the train is approaching and leaving the wake, which is caused by the vehicle relative movement to the tower, as has been proposed by Charuvisit et al. [30] that the vehicle motion modifies the steady state aerodynamic condition and introduces an asymmetry in the aerodynamic loads on the vehicle when it passes through the tower. The asymmetric results are clearly distinguished from the conventional static ones and will be detailed discussed in future work.

\subsection{Effect of wind speed}

When the effect of the Reynolds number is not taken into account, the aerodynamic coefficient is the function of wind angle and yaw angle [21]. The wind angle discussed in this study is $90^{\circ}$, therefore the aerodynamic coefficient is only a function of yaw angle, which can be changed by changing the incoming wind speed or train speed. However, the aerodynamic characteristics of vehicles at the same yaw angle (composed of different wind speed and train speed) are quite different. Therefore, it is necessary to study the aerodynamic coefficients of vehicles under different incoming wind speeds or vehicle speeds. When the

Table 1 Influencing width of sudden change area for case with tower

\begin{tabular}{lllll}
\hline Items & $x_{1}(\mathrm{~m})$ & $x_{2}(\mathrm{~m})$ & $d_{\mathrm{s}}(\mathrm{m})$ & $d_{\mathrm{s}} / d_{\mathrm{t}}$ \\
\hline$C_{\mathrm{L}}$ & -0.574 & 0.703 & 1.277 & 1.93 \\
$C_{\mathrm{S}}$ & -0.711 & 0.840 & 1.551 & 2.35 \\
$C_{\mathrm{R}}$ & -0.850 & 1.006 & 1.856 & 2.81 \\
\hline
\end{tabular}

$x_{1}$ and $x_{2}$ are the initial and last intersecting positions, respectively; $d_{\mathrm{s}}$ is the influencing width of sudden change area; and $d_{\mathrm{t}}$ is the width of tower 

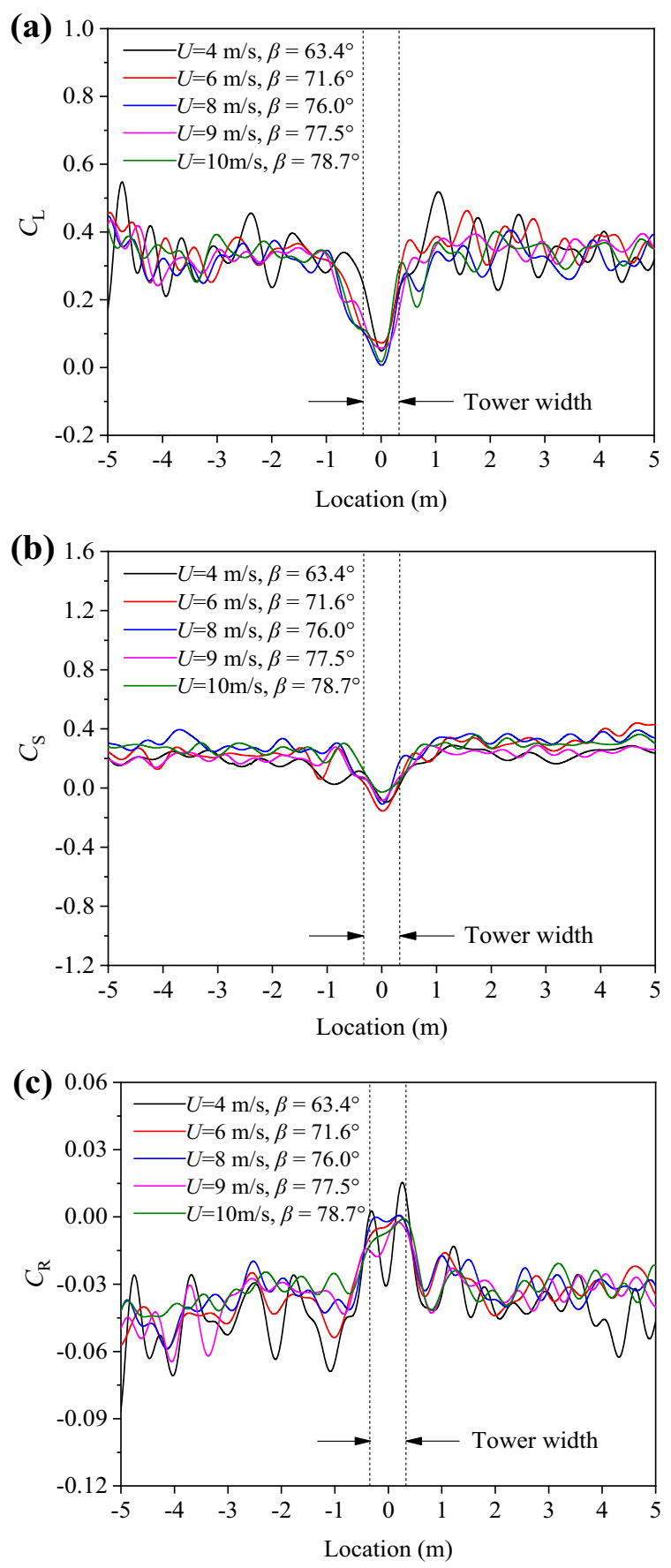

Fig. 15 Aerodynamic coefficients of train varying with wind speed at low train speed of $V=2 \mathrm{~m} / \mathrm{s}$ : a lift force coefficient $C_{\mathrm{L}}$; b side force coefficient $C_{\mathrm{S}}$; c rolling moment coefficient $C_{\mathrm{R}}$

wind speed is $4-10 \mathrm{~m} / \mathrm{s}$, the aerodynamic coefficients of the train varying with the wind speed under a low train speed of $V=2 \mathrm{~m} / \mathrm{s}$ and a high train speed of $V=12 \mathrm{~m} / \mathrm{s}$ are as shown in Figs. 15 and 16, respectively.

It can be seen from Fig. 15 that at low train speed, when the train is in the region of approaching tower, the aerodynamic coefficients of the vehicle generally do not change
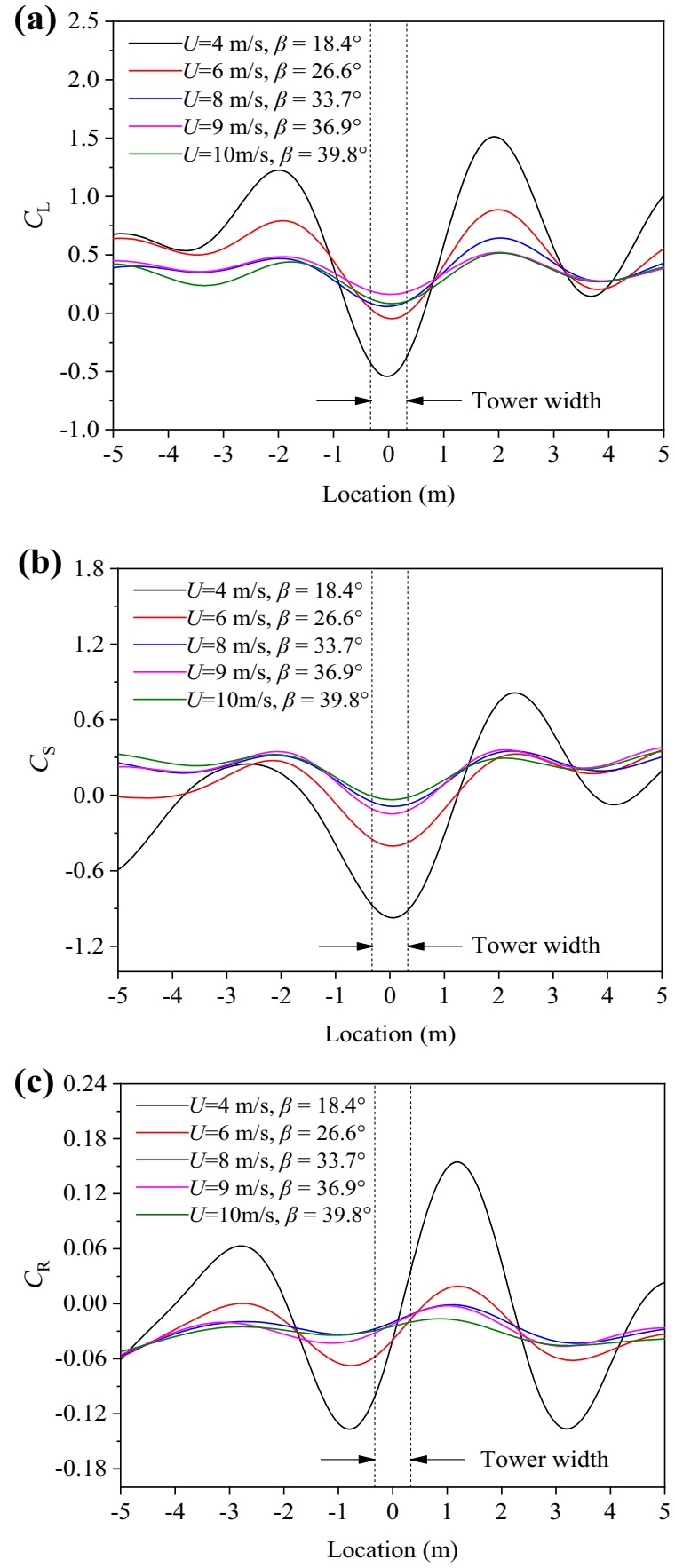

Fig. 16 Aerodynamic coefficients of train varying with wind speed at high train speed of $V=12 \mathrm{~m} / \mathrm{s}$ : a lift force coefficient $C_{\mathrm{L}}$; b side force coefficient $C_{\mathrm{S}}$; c rolling moment coefficient $C_{\mathrm{R}}$

significantly with the incoming wind speed, except the side force coefficient at the wind speed $U=4 \mathrm{~m} / \mathrm{s}$ is negative, which may be caused by the test contingency. In the process of crossing through the tower, the aerodynamic coefficients of the train appear great mutations, yet no obvious change with the wind speed. It is worth noting that under different wind speeds, the side force coefficient decreases 
abruptly from positive value to negative value, and then increases to positive value, changing direction continuously, which will be extremely detrimental to the train operation safety. After the train leaves the tower, the aerodynamic coefficients of the vehicle return to the same as that in the region of approaching tower.

It can be seen from Fig. 16 that at high train speed, when the train is approaching the tower, the aerodynamic coefficients of the vehicle fluctuate notably with the change of wind speed, which is entirely different from that at low train speed. On the whole, the lift force coefficient decreases with the increase of wind speed. The side force coefficient increases with the increase of wind speed and changes from negative region to positive region. The rolling moment coefficient decreases with the increase of wind speed, changing direction from positive to negative value. The direction of the side force and rolling moment on the train has changed. Under some combinations, potential safety hazard may exist for train operation. In the process of the train passing through the tower, the lift force coefficient and the side force coefficient have a distinct mutation while the rolling moment coefficient does not. In fact, the sudden change of the rolling moment coefficient is more serious, with the direction changing continuously back and forth between the positive and negative area. The smaller the incoming wind speed, the greater the abrupt change of each aerodynamic coefficient as well as the fluctuation, which has the reverse effect at high wind speeds. Compared with the low train speed case of $V=12 \mathrm{~m} / \mathrm{s}$, it exactly shows the complexity of the flow field around the bridge tower with the train running at a high train speed. The influence of the vehicle motion must be considered. Meanwhile, the results are also consistent with that in Fig. 18c, i.e., the smaller the yaw angle (the smaller the incoming wind speed), the larger the mutation amplitude of aerodynamic coefficients when the train passes by the bridge tower under a high train speed. When the train is leaving the tower, a local enlargement appears for the aerodynamic coefficients especially at a low incoming wind speed, which is caused by the wake effect of the bridge tower. Furthermore, the aerodynamic coefficients display asymmetry in the process of approaching and leaving the tower, consistent with the results in Charuvisit et al. [30].

\subsection{Effect of train speed}

The flow field around a train in motion is quite different from that at rest. In order to better analyze the influence of the vehicle movement on aerodynamic coefficients, changes of the aerodynamic coefficients with the yaw angle $\left(33.7^{\circ}-76.0^{\circ}\right)$ under two definitions are shown in Figs. 17 and 18 , respectively, when the incoming wind speed is
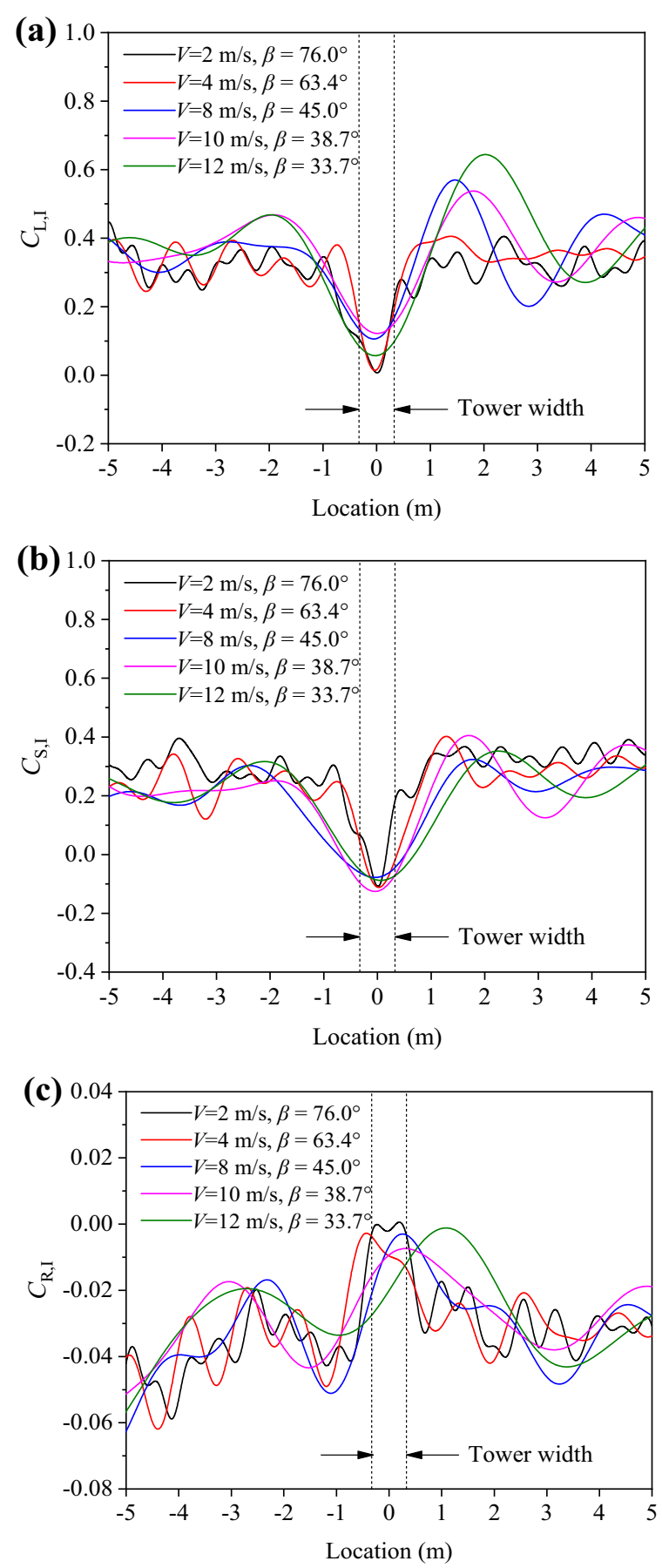

Fig. 17 Aerodynamic coefficients of train varying with vehicle speed under the first definition: a lift force coefficient $C_{\mathrm{L}, \mathrm{I}}$; b side force coefficient $C_{\mathrm{S}, \mathrm{I}}$; c rolling moment coefficient $C_{\mathrm{R}, \mathrm{I}}$

$8 \mathrm{~m} / \mathrm{s}$ and the train speed is $2-12 \mathrm{~m} / \mathrm{s}$. We can find that the variation law of vehicle aerodynamic coefficients with the yaw angle is various with different definitions. Under the second definition, when the train is approaching the tower, the mean values of aerodynamic coefficients are consistent with the changing laws in Li et al. [33], that is, the lift force coefficient and the side force coefficient increase, and the 

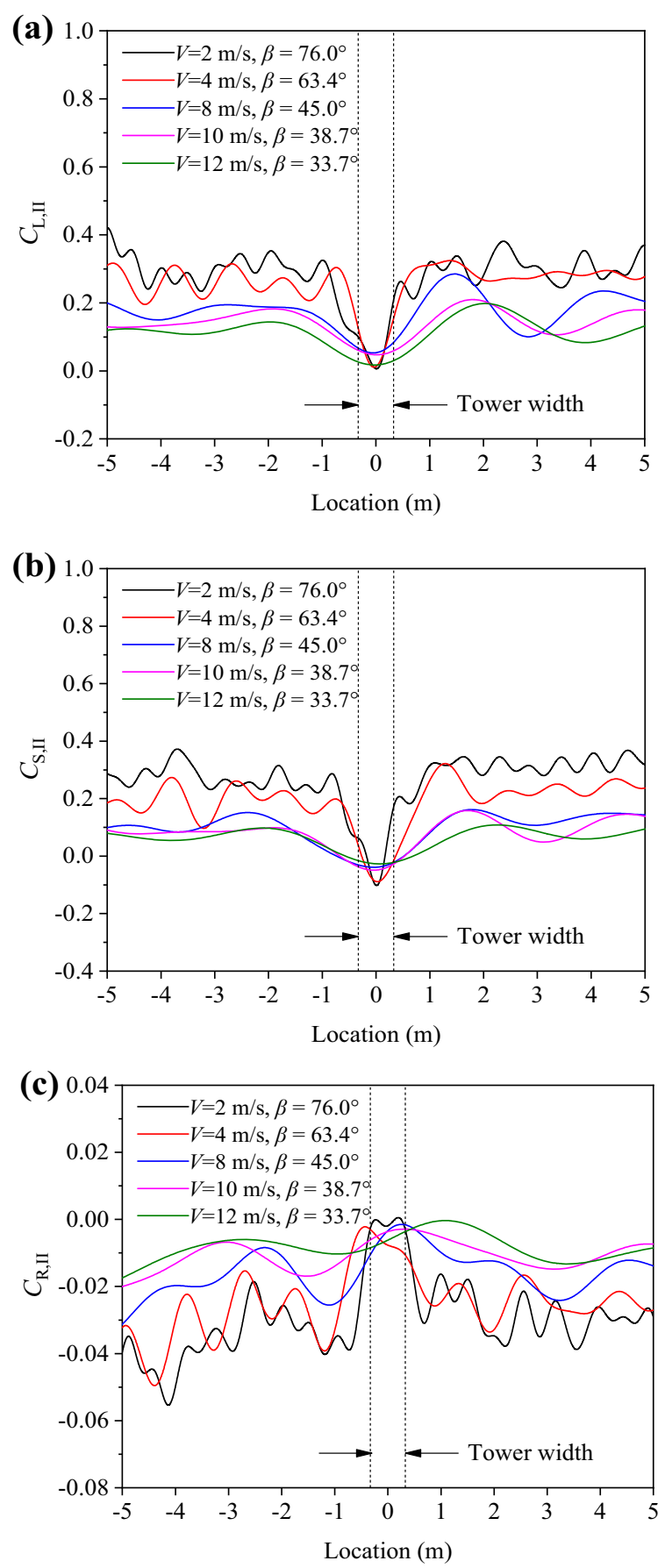

Fig. 18 Aerodynamic coefficients of train varying with vehicle speed under the second definition: a lift force coefficient $C_{\mathrm{L}, \mathrm{II}}$; $\mathbf{b}$ side force coefficient $C_{\mathrm{S}, \mathrm{II}} ; \mathbf{c}$ rolling moment coefficient $C_{\mathrm{R}, \mathrm{II}}$

rolling moment coefficient decreases with the increase of the yaw angle.

In this study, the first definition is used to describe the aerodynamic characteristics of the train at different stages when it passes through the bridge tower. It can be seen that when the train does not enter the tower region, the aerodynamic coefficients of the train do not change significantly with the train speed, which is completely different from that in the second definition after $\sin ^{2} \beta$ conversion. When the train is in the tower shielding area, the aerodynamic coefficients of the train all experience great mutations. Different from that in Sect. 4.2, the influencing widths of aerodynamic coefficients under various train speeds are different. Generally, with the increase of the train speed, the influencing widths of aerodynamic coefficients in the tower shielding region increase. While in Sect. 4.2 where the train speed is constant, the difference of the influencing width is not significant, indicating that the train speed is an important factor affecting the influencing widths of aerodynamic coefficients. With the shielding effect of the bridge tower, the lift force coefficient first decreases and then increases, and the mutation amplitudes under different train speeds are various. The side force coefficient experiences a sudden change with direction of the side force acting on the train changed continuously, and the mutation amplitudes vary little under various train speeds. The rolling moment coefficient presents an obvious "sudden change" phenomenon under low train speed, while no obvious this kind of phenomenon at high train speed, which are consistent with the results in Figs. 15c and $16 \mathrm{c}$.

After the train leaves the bridge tower, the influence of the tower shielding effect on wind forces on the train gradually weakens. However, the aerodynamic coefficients of the train increase partially due to the vehicle movement, and the higher the train speed, the more obvious the partial increase of the lift force coefficient and the side force coefficient. After a certain distance away from the bridge tower, the aerodynamic coefficients of the vehicle return to that before entering the bridge tower area.

The influencing widths of aerodynamic coefficients under the two definitions are consistent. The variation of the influencing widths with the train speed is shown in

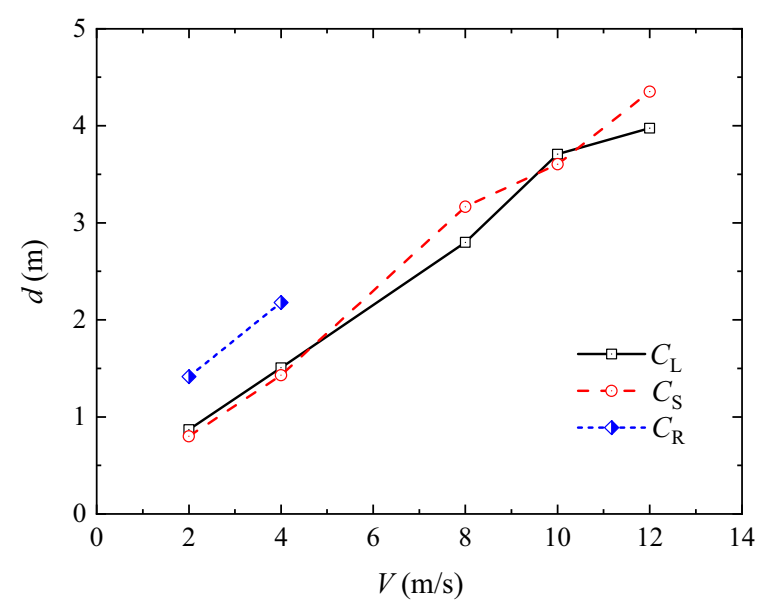

Fig. 19 Influencing widths varying with train speed $(U=8 \mathrm{~m} / \mathrm{s})$ 
Fig. 19. It can be seen that the higher the train speed, the greater the influencing widths of the curve in tower shielding area. The influencing width of aerodynamic coefficients has a positive correlation with the train speed. From the perspective of the wave mechanism, the relationship among the speed, wavelength $\lambda$ and frequency $f$ is $V=\lambda f$. The vibration frequency of the car body is constant, hence the higher the train speed, the larger the wavelength of the curve, and the greater the influencing width. When the train passes through the bridge tower, the influence range of the tower on the train covers several wavelengths, and the aerodynamic characteristics of the train within this range will be affected and reflected as "sudden change". The influencing widths corresponding to the curves of different wavelengths are also inconsistent. The higher the train speed (the larger the wavelength), the smaller the slope of the sudden decrease, and the larger the influencing width of aerodynamic coefficients. One can also find that the influencing width of the rolling moment coefficient is larger than that of the lift force coefficient and the side force coefficient, and the influencing width of the lift force coefficient and the side force coefficient is close to each other.

Taking the influencing width of the side force coefficient as an example, as shown in Table 2, when the train speed is $2 \mathrm{~m} / \mathrm{s}$, the influencing width in the tower shielding area is $0.80 \mathrm{~m}, 1.21$ times of the width of the bridge tower; when the train speed is $12 \mathrm{~m} / \mathrm{s}$, the influencing width is $4.35 \mathrm{~m}$, 6.59 times of the width of the bridge tower. The influencing width of aerodynamic coefficients is positively correlated with the train speed.

\subsection{Effect of yaw angle}

By analyzing Figs. 15 and 16, the variations of the influencing width of aerodynamic coefficients with the yaw angle at low and high vehicle speeds are obtained, as

Table 2 Influencing widths of train aerodynamic coefficients

\begin{tabular}{|c|c|c|c|c|c|c|}
\hline \multirow[t]{2}{*}{$V(\mathrm{~m} / \mathrm{s})$} & \multicolumn{2}{|l|}{$C_{\mathrm{L}}$} & \multicolumn{2}{|l|}{$C_{\mathrm{S}}$} & \multicolumn{2}{|l|}{$C_{\mathrm{R}}$} \\
\hline & $d_{\mathrm{s}}(\mathrm{m})$ & $d_{\mathrm{s}} / d_{\mathrm{t}}$ & $d_{\mathrm{s}}(\mathrm{m})$ & $d_{\mathrm{s}} / d_{\mathrm{t}}$ & $d_{\mathrm{s}}(\mathrm{m})$ & $d_{\mathrm{s}} / d_{\mathrm{t}}$ \\
\hline 2 & 0.87 & 1.32 & 0.80 & 1.21 & 1.41 & 2.14 \\
\hline 4 & 1.51 & 2.28 & 1.43 & 2.17 & 2.18 & 3.30 \\
\hline 8 & 2.80 & 4.24 & 3.17 & 4.80 & - & - \\
\hline 10 & 3.71 & 5.62 & 3.60 & 5.46 & - & - \\
\hline 12 & 3.97 & 6.02 & 4.35 & 6.59 & - & - \\
\hline
\end{tabular}

shown in Fig. 20. It can be seen that the influencing widths of vehicle aerodynamic coefficients vary little with the yaw angle under low and high train speed, respectively, which suggests that the effect of the wind speed on the influencing width of aerodynamic coefficients is not significant at a certain train speed. The influencing widths of aerodynamic coefficients at high train speed are larger than that at low train speed. Taking the wind speed of $4 \mathrm{~m} / \mathrm{s}$ as an example, the influencing widths of the lift force coefficient, side force coefficient, and rolling moment coefficient under low train speed are $0.816,0.873$, and $1.390 \mathrm{~m}$, respectively, which are $1.23,1.32$, and 2.11 times the width of the bridge tower itself $(0.66 \mathrm{~m})$. While under high train speed, the influencing widths of the lift force coefficient and the side force coefficient are 3.904 and $4.387 \mathrm{~m}$, respectively, increased by 5.92 and 6.65 times, which is much larger than the width of the bridge tower. The higher the vehicle speed, the larger the influencing width of the vehicle aerodynamic coefficients. When the vehicle speed is constant, the influencing width has no significant change, which also implies that the vehicle speed is a critical factor affecting the influencing width of aerodynamic coefficients. From Figs. 15 and 16, we can also find that the shielding effect of the bridge tower, reflected in the influencing width, has the greatest impact on the rolling moment of the vehicle, and then the side force and the lift force.

The variation of the mutation amplitude of aerodynamic coefficients with the yaw angle under the two definitions is shown in Fig. 21. It was discovered that the variation trend of the mutation amplitude of aerodynamic coefficients with the yaw angle is different under different definitions. Outside of the tower area, the changing law of the mutation amplitude under two definitions are inconsistent. In the shelter area of the tower, the variation of the mutation amplitude of aerodynamic coefficients with the yaw angle is also related to the definition adopted.

Under the first definition, when $33.7^{\circ} \leq \beta \leq 45^{\circ}$, the mutation amplitude of aerodynamic coefficients decreases with the increase of the yaw angle (the rolling moment coefficient considers the absolute value). While when $45^{\circ} \leq \beta \leq 76.0^{\circ}$, the mutation amplitude began to level off with the increase of the yaw angle, which is consistent with that in Sect. 4.4 , that is, $\beta=45^{\circ}$ is the critical yaw angle of the mutation amplitude. Under the second definition, when $33.7^{\circ} \leq \beta \leq 76.0^{\circ}$, the mutation amplitude of aerodynamic coefficients increases with the increase of the yaw angle with no critical value (the rolling moment coefficient is not 

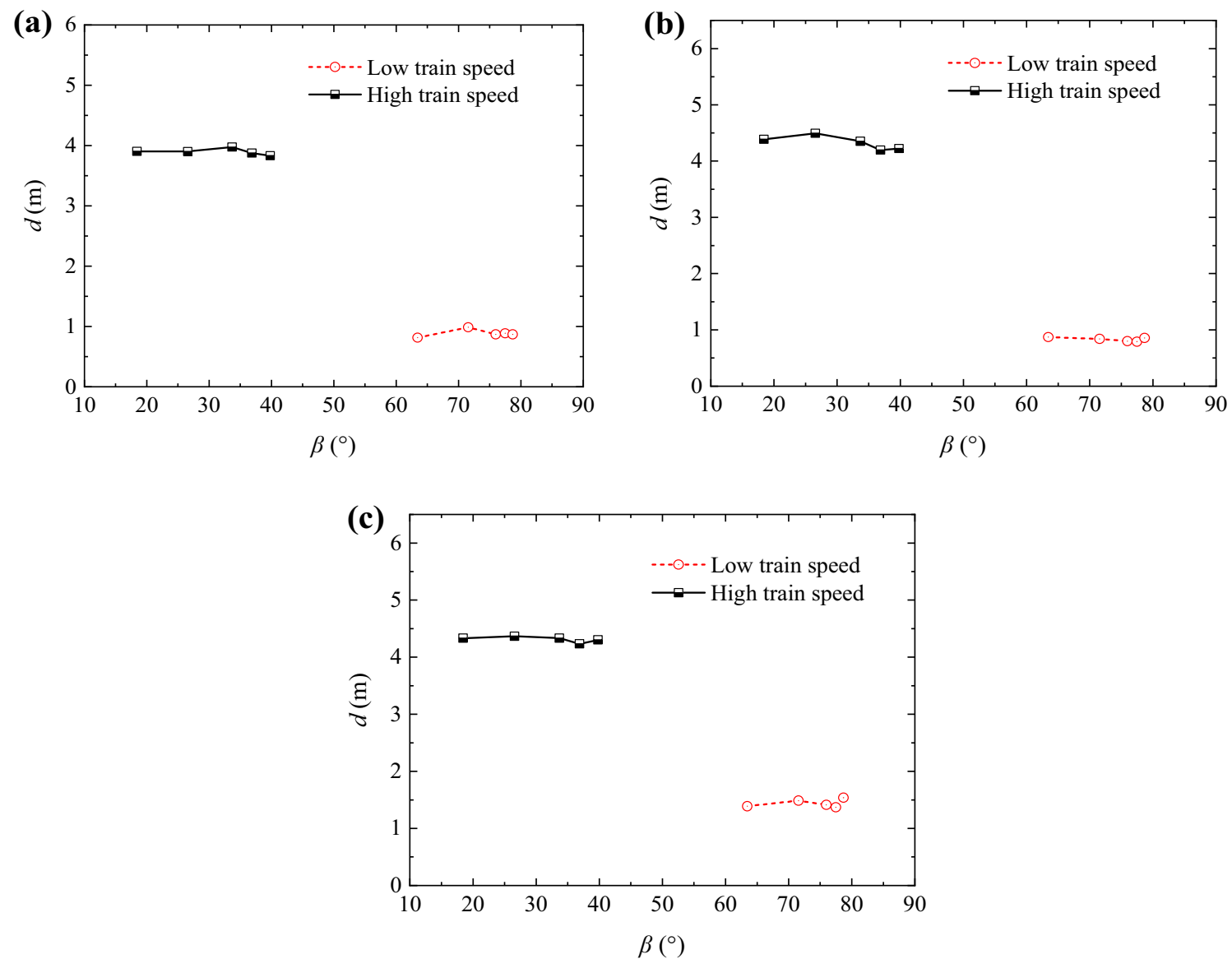

Fig. 20 Influencing width of aerodynamic coefficients varying with yaw angle: a lift force coefficient; $\mathbf{b}$ side force coefficient; $\mathbf{c}$ rolling moment coefficient

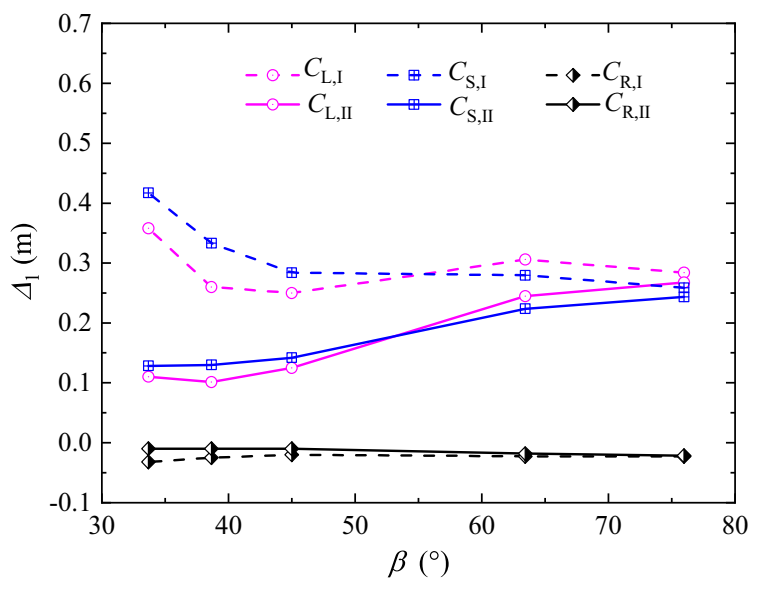

Fig. 21 Mutation amplitude of aerodynamic coefficients varying with yaw angle under two definitions $(U=8 \mathrm{~m} / \mathrm{s})$ obvious because of its small value), and it is close to the mutation amplitude in the first definition when the yaw angle is large (e.g., $\beta=76.0^{\circ}$ ).

The curves of the mutation amplitude of aerodynamic coefficients with the yaw angle at $V=2 \mathrm{~m} / \mathrm{s}, V=12 \mathrm{~m} / \mathrm{s}$, and $U=8 \mathrm{~m} / \mathrm{s}$ are plotted together and are shown in Fig. 22. It can be seen that the mutation amplitude curves of $V=2 \mathrm{~m} / \mathrm{s}$ and $V=12 \mathrm{~m} / \mathrm{s}$ are in good agreement with the trend under $U=8 \mathrm{~m} / \mathrm{s}$. Specifically, at small yaw angle, the mutation amplitude of the lift force coefficient and the side force coefficient decrease with the increase of the yaw angle, while the mutation amplitude of the rolling moment coefficient increases with the increase of the yaw angle. When $\beta$ is between $40^{\circ}$ to $45^{\circ}$, the mutation amplitude of aerodynamic coefficients begins to flatten. When $\beta \geq 45^{\circ}$, the mutation amplitude of aerodynamic coefficients has no obvious change with the yaw angle. 

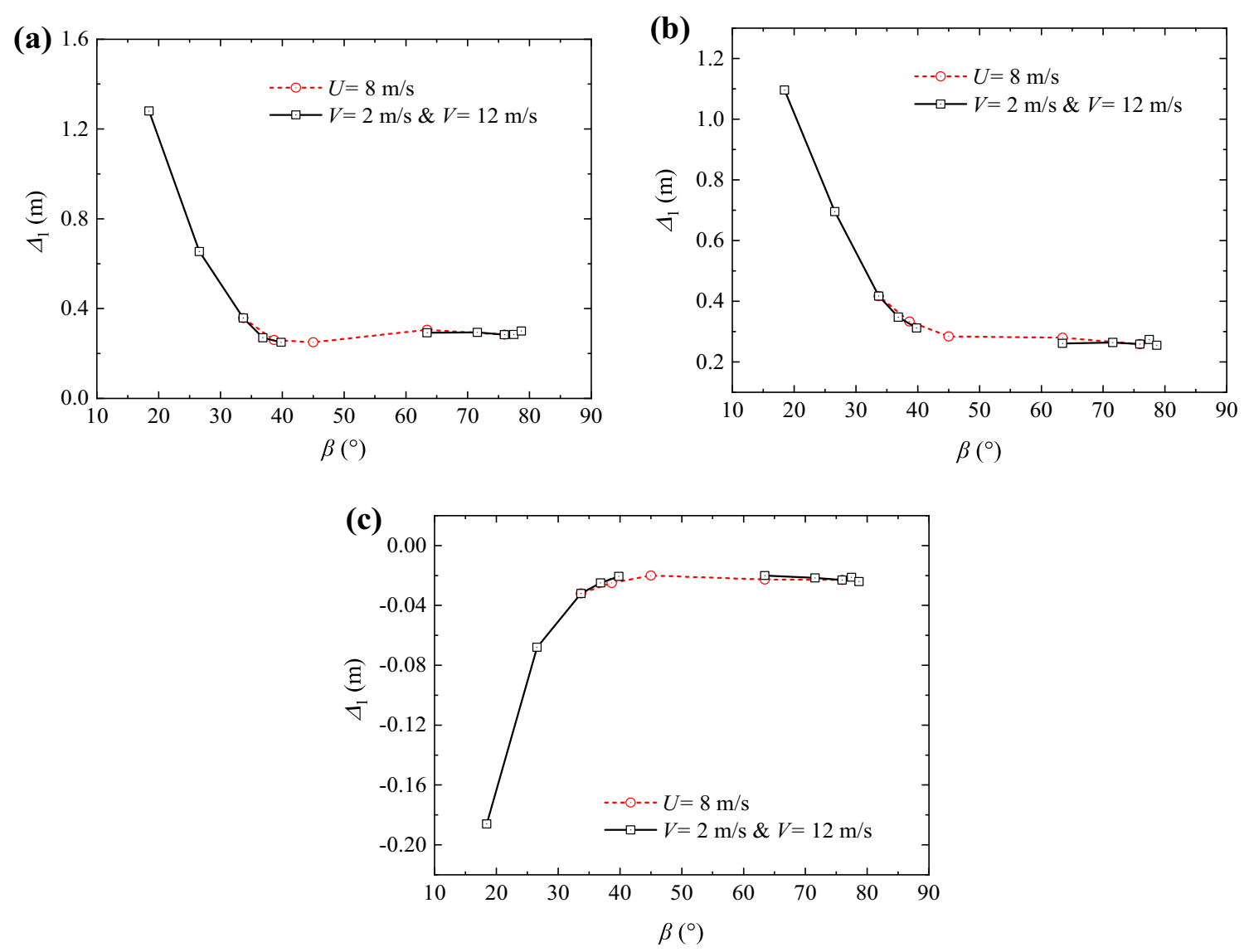

Fig. 22 Mutation amplitude of aerodynamic coefficients vary with yaw angle: a lift force coefficient; $\mathbf{b}$ side force coefficient; $\mathbf{c}$ rolling moment coefficient

\section{Concluding remarks}

In this study, the wind tunnel experiments have been performed to obtain the aerodynamic forces acting on a moving train model as it passes by a bridge tower. The influences of wind speed, train speed, and yaw angle on the shielding effect are analyzed by focusing on the influenced width and mutation amplitude of aerodynamic coefficients. The following conclusions can be drawn:

(1) The bridge tower shows an obvious shielding effect on the train passing through it, where the aerodynamic coefficients of the train reach their mutation peak values with the train being behind the tower shielding area.

(2) The influencing width of bridge tower shielding on train aerodynamic coefficients is much larger than the width of the bridge tower itself and is considerably affected by the train speed while the incoming wind speed has little effect on it.

(3) The mutation amplitude is significantly influenced by the train and wind speeds. In terms of yaw angle, the absolute mutation amplitude in three force aerodynamic coefficients decrease firstly with the yaw angle increases, then tend to be stable when yaw angle beyond $45^{\circ}$.

The presented study represents the first step of a larger research project, which aims at investigating the sudden change mechanism of aerodynamic forces acting on trains caused by the wake of the bridge tower, also considering train motions. The next step of the study will make a further discussion on the train aerodynamic performance as it passes through the wake with localized wind barriers near the tower. Moreover, with the further advancement of experiment capacity, aerodynamic characteristics of the head car with a more complicated flow field should be investigated in future.

Acknowledgements The authors would like to gratefully acknowledge the supports from the National Natural Science Foundation of China (No. U1434205, 51708645) and Zhejiang Provincial Natural Science Foundation of China (No. LY19E080016).

Open Access This article is licensed under a Creative Commons Attribution 4.0 International License, which permits use, sharing, adaptation, distribution and reproduction in any medium or format, as long as you give appropriate credit to the original author(s) and the 
source, provide a link to the Creative Commons licence, and indicate if changes were made. The images or other third party material in this article are included in the article's Creative Commons licence, unless indicated otherwise in a credit line to the material. If material is not included in the article's Creative Commons licence and your intended use is not permitted by statutory regulation or exceeds the permitted use, you will need to obtain permission directly from the copyright holder. To view a copy of this licence, visit http://creativecommons. org/licenses/by/4.0/.

\section{References}

1. Chen SR, Cai CS (2006) Unified approach to predict the dynamic performance of transportation system considering wind effects. Struct Eng Mech 23:279-292

2. Guo WW, Xu YL, Xia H, Zhang WS, Shum KM (2007) Dynamic response of suspension bridge to typhoon and trains. II: numerical results. J Struct Eng 133:12-21

3. Xia H, Guo WW, Zhang N, Sun GJ (2008) Dynamic analysis of a train-bridge system under wind action. Comput Struct 86:1845-1855

4. Li YL, Xiang HY, Wang B, Xu YL, Qiang SZ (2013) Dynamic analysis of wind-vehicle-bridge coupling system during the meeting of two trains. Adv Struct Eng 16:1663-1670

5. Xu YL, Guo WH (2003) Dynamic analysis of coupled road vehicle and cable-stayed bridge systems under turbulent wind. Eng Struct 25:473-486

6. Cai CS, Chen SR (2004) Framework of vehicle-bridge-wind dynamic analysis. J Wind Eng Ind Aerodyn 92:579-607

7. Li YL, Qiang SZ, Liao HL, Xu YL (2005) Dynamics of wind-rail vehicle-bridge systems. J Wind Eng Ind Aerodyn 93:483-507

8. Xu L, Zhai W (2020) Train-track coupled dynamic analysis: system spatial variation on geometry, physics and mechanics. Railw Eng Sci 28:36-53

9. Xu L, Zhai W (2021) Vehicle-track-tunnel dynamic interaction: a finite/infinite element modelling method. Railw Eng Sci 29:109-126

10. Liu DJ, Li XZ, Ma SH, Wu JF (2015) Study of coupling vibration of wind-train-track-bridge system for main ship channel bridge of Hutong Changjiang River Bridge. Bridge Constr 45:24-29 (in Chinese)

11. Gao WB, Su QK, Zhang JW, Xie HB, Wen F, Li F, Liu JZ (2020) Steel bridge construction of Hong Kong-Zhuhai-Macao Bridge. Int J Steel Struct 20:1498-1508

12. Xu HL (2007) Xihoumen Bridge-Zhoushan Island Linking Project. In: Proceedings of the 24th Annual International Bridge Conference, Pittsburgh, Oct 29-Nov 2, 2007, pp 40-51

13. Zhou Q, Zhu LD (2020) Numerical and experimental study on wind environment at near tower region of a bridge deck. Heliyon 6:e03902

14. Zhang JY, Zhang MJ, Huang B, Li YL, Yu JX, Jiang FY (2021) Wind tunnel test on local wind field around the bridge tower of a truss girder. Adv Civ Eng 2021:1-13

15. Chen SR, Cai CS (2004) Accident assessment of vehicles on long-span bridges in windy environments. J Wind Eng Ind Aerodyn 92:991-1024

16. Snæbjörnsson JT, Baker CJ, Sigbjörnsson R (2007) Probabilistic assessment of road vehicle safety in windy environments. J Wind Eng Ind Aerodyn 95:1445-1462

17. Sterling M, Quinn AD, Hargreaves DM, Cheli F, Sabbioni E, Tomasini G, Delaunay D, Baker CJ, Morvan H (2010) A comparison of different methods to evaluate the wind induced forces on a high sided lorry. J Wind Eng Ind Aerodyn 98:10-20
18. Dorigatti F, Sterling M, Rocchi D, Belloli M, Quinn AD, Baker CJ, Ozkan E (2012) Wind tunnel measurements of crosswind loads on high sided vehicles over long span bridges. J Wind Eng Ind Aerodyn 107-108:214-224

19. Zhu LD, Li L, Xu YL, Zhu Q (2012) Wind tunnel investigations of aerodynamic coefficients of road vehicles on bridge deck. J Fluids Struct 30:35-50

20. Liu X, Han Y, Cai CS, Levitan M, Nikitopoulos D (2016) Wind tunnel tests for mean wind loads on road vehicles. J Wind Eng Ind Aerodyn 150:15-21

21. Baker CJ (1986) Train aerodynamic forces and moments from moving model experiments. J Wind Eng Ind Aerodyn 24:227-251

22. Cairns RS (1994) Lateral aerodynamic characteristics of motor vehicles in transient crosswinds. Dissertation, Cranfield University

23. Li Y, Hu P, Xu Y, Zhang M, Liao H (2014) Wind loads on a moving vehicle-bridge deck system by wind-tunnel model test. Wind Struct 19:145-167

24. Bocciolone M, Cheli F, Corradi R, Muggiasca S, Tomasini G (2008) Crosswind action on rail vehicles: wind tunnel experimental analyses. J Wind Eng Ind Aerodyn 96:584-610

25. Dorigatti F, Sterling M, Baker CJ, Quinn AD (2015) Crosswind effects on the stability of a model passenger train-a comparison of static and moving experiments. J Wind Eng Ind Aerodyn 138:36-51

26. Xiang H, Li Y, Chen S, Li C (2017) A wind tunnel test method on aerodynamic characteristics of moving vehicles under crosswinds. J Wind Eng Ind Aerodyn 163:15-23

27. Rocchi D, Rosa L, Sabbioni E, Sbrosi M, Belloli M (2012) A numerical-experimental methodology for simulating the aerodynamic forces acting on a moving vehicle passing through the wake of a bridge tower under cross wind. J Wind Eng Ind Aerodyn 104-106:256-265

28. Li Y, Hu P, Cai CS, Zhang M, Qiang S (2013) Wind tunnel study of a sudden change of train wind loads due to the wind shielding effects of bridge towers and passing trains. J Eng Mech 139:1249-1259

29. Salati L, Schito P, Rocchi D, Sabbioni E (2018) Aerodynamic study on a heavy truck passing by a bridge pylon under crosswinds using CFD. J Bridge Eng 23:04018065

30. Charuvisit S, Kimura K, Fujino Y (2004) Experimental and semianalytical studies on the aerodynamic forces acting on a vehicle passing through the wake of a bridge tower in cross wind. J Wind Eng Ind Aerodyn 92:749-780

31. Argentini T, Ozkan E, Rocchi D, Rosa L, Zasso A (2011) Crosswind effects on a vehicle crossing the wake of a bridge pylon. J Wind Eng Ind Aerodyn 99:734-740

32. Wang B, Xu YL, Zhu LD, Li YL (2014) Crosswind effect studies on road vehicle passing by bridge tower using computational fluid dynamics. Eng Appl Comput Fluid Mech 8:330-344

33. Li XZ, Wang M, Xiao J, Zou QY, Liu DJ (2018) Experimental study on aerodynamic characteristics of high-speed train on a truss bridge: a moving model test. J Wind Eng Ind Aerodyn 179:26-38

34. Wang M, Li XZ, Xiao J, Zou QY, Sha HQ (2018) An experimental analysis of the aerodynamic characteristics of a highspeed train on a bridge under crosswinds. J Wind Eng Ind Aerodyn 177:92-100

35. Yao Z, Zhang N, Chen X, Zhang C, Xia H, Li X (2020) The effect of moving train on the aerodynamic performances of trainbridge system with a crosswind. Eng Appl Comput Fluid Mech 14:222-235

36. Cooper RK (1979) The effect of cross-winds on trains. In: Proceedings of the ASME-CSME Conference on Aerodynamics of Transportation. Niagara, June 18-20 
37. Cheli F, Corradi R, Rocchi D, Tomasini G, Maestrini E (2010) Wind tunnel tests on train scale models to investigate the effect of infrastructure scenario. J Wind Eng Ind Aerodyn 98:353-362

38. Tomasini G, Giappino S, Corradi R (2014) Experimental investigation of the effects of embankment scenario on railway vehicle aerodynamic coefficients. J Wind Eng Ind Aerodyn 131:59-71

39. He XH, Zou YF, Wang HF, Han Y, Shi K (2014) Aerodynamic characteristics of a trailing rail vehicles on viaduct based on still wind tunnel experiments. J Wind Eng Ind Aerodyn 135:22-33

40. Wang M, Li XZ, Xiao J, Sha HQ, Zou QY (2020) Effects of infrastructure on the aerodynamic performance of a high-speed train. Proc IMechE Part F J Rail Rapid Transit 235:679-689

41. Li X, Tan Y, Qiu X, Gong Z, Wang M (2021) Wind tunnel measurement of aerodynamic characteristic of trains passing each other on a simple supported box girder bridge. Railw Eng Sci 29:152-162

42. Sabbioni E, Sbrosi M, Rocchi D, Galeotti R (2012) Dynamic response of vehicle-driver couple to the aerodynamic loads due to the crossing of a bridge tower wake. SAE Int J Commer Veh 5:83-93

43. Wang B, Xu YL (2015) Safety analysis of a road vehicle passing by a bridge tower under crosswinds. J Wind Eng Ind Aerodyn 137:25-36

44. Wang Y, Zhang Z, Zhang Q, Hu Z, Su C (2021) Dynamic coupling analysis of the aerodynamic performance of a sedan passing by the bridge pylon in a crosswind. Appl Math Model 89:1279-1293 